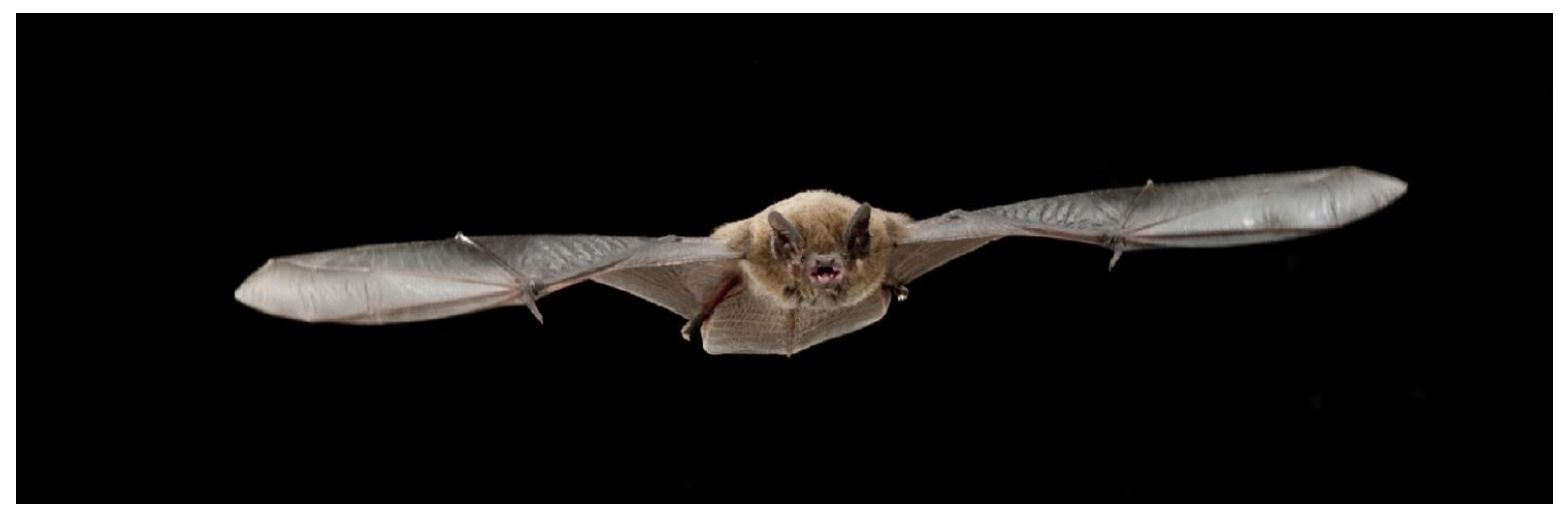

\title{
Bats at the southern North Sea in 2017 \& 2018
}

Author(s): Sander Lagerveld, Jan Tjalling van der Wal, Pepijn de Vries, Hans Verdaat, Cor Sonneveld, Jaap van der Meer, Robin Brabant \& Bart Noort
Wageningen University \&

Research report C062/19 


\section{Bats at the southern North Sea in 2017 \& 2018}

Author(s): $\quad$ Sander Lagerveld, Jan Tjalling van der Wal, Pepijn de Vries, Hans Verdaat, Cor Sonneveld, Jaap van der Meer, Robin Brabant \& Bart Noort 
Keywords: Bats, bat migration, offshore wind energy, bat detector research

Client: $\quad$ Rijkswaterstaat

Attn.: Ingeborg van Splunder

Postbus 2232

3500 GE Utrecht

This report can be downloaded for free from https://doi.org/10.18174/496171

Wageningen Marine Research provides no printed copies of reports

Wageningen Marine Research is ISO 9001:2015 certified.

Photo cover: René Janssen

\section{(C) Wageningen Marine Research}

Wageningen Marine Research, an institute Wageningen Marine Research accepts no liability for consequential damage, nor within the legal entity Stichting for damage resulting from applications of the results of work or other data Wageningen Research (a foundation under obtained from Wageningen Marine Research. Client indemnifies Wageningen Dutch private law) represented by Dr. Marine Research from claims of third parties in connection with this application. M.C.Th. Scholten, Managing Director All rights reserved. No part of this publication may be reproduced and / or

KvK nr. 09098104, published, photocopied or used in any other way without the written permission WMR BTW nr. NL 8113.83.696.B16.

Code BIC/SWIFT address: RABONL2U IBAN code: NL 73 RABO 0373599285 


\section{Contents}

Bats at the southern North Sea in 2017 \& 2018

\section{Contents}

1 Introduction

1.1 Background

1.2 Project team

1.3 Acknowledgements

$2 \quad$ Materials and Methods

2.1 Study area

2.2 Heading 2

2.3 Heading 2

2.2 Equipment

2.3 Data management

2.4 Analysis

2.4.1 Occurrence

2.4.2 Comparison performance Avisoft \& Batcorder $\quad 11$

2.4.3 Differences in abundance and timing

3 Results

$3.1 \quad$ Monitoring effort

3.2 Occurrence of bats per monitoring location 15

3.3 Comparison Avisoft and Batcorder $\quad 18$

3.4 Variability amongst monitoring locations and years $\quad 20$

3.5 Variability in timing $\quad 22$

4 Discussion and conclusions $\quad 27$

$\begin{array}{lll}4.1 & \text { Monitoring results } 2017 / 2018 & 27\end{array}$

$\begin{array}{ll}4.2 & \text { Acoustic monitoring with Avisoft and Batcorder } \\ 4.3 & 27\end{array}$

$\begin{array}{lll}4.3 & \text { Variation in time and in space } & 28\end{array}$

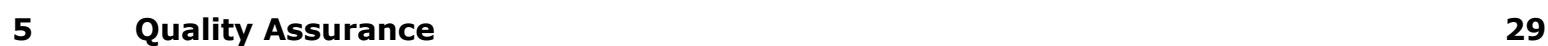

$\begin{array}{lr}\text { References } & 30\end{array}$

$\begin{array}{lr}\text { Justification } & 32\end{array}$ 


\section{Summary}

Numerous land-based studies have shown that wind farms can have a significant negative effect on bat populations due to collisions and barotrauma. Since a few years it is also known that bats migrate regularly over the North Sea. In order to reduce uncertainties about possible impacts of the development of the offshore wind sector Rijkswaterstaat commissioned a follow-up offshore bat monitoring project as part of the WOZEP programme (Offshore Wind Ecological Programme). The monitoring will continue until at least 2019 and possibly throughout 2020. After that, the final report will be compiled, which will include a spatiotemporal analysis of the offshore occurrence of bats in all previous monitoring years. This report provides an overview of the monitoring effort and monitoring results in $2017 \& 2018$.

Currently there are 14 monitoring locations where acoustic bat monitoring is executed, of which seven are oil \& gas rigs, five are offshore high voltage stations of offshore wind farms and two are measurement platforms (Lichteiland Goeree and Europlatform). Since 2017 a new type of batdetector (Avisoft) is applied. In order to assess differences between the previously used batdetector (Batcorder) we monitored simultaneously with both detectors at three monitoring locations.

The monitoring results in 2017 and 2018 show the same general pattern of occurrence as in previous years with Nathusius pipistrelle being the most common species, and Common pipistrelles and 'Nyctaloids' much more scarce.

Furthermore the differences in performance are discussed between the currently used Avisoft detector and the previously used Batcorder. It appears that a correction should be applied in order to make measurements comparable between the two detectors, and the value of this correction factor depends on the time interval used in the analysis. At this moment the precision of the correction factor is estimated at 1.17 for 10 minute time intervals. In order to improve the precision to 1.1 simultaneous monitoring by both detectors should continue at least two monitoring years.

Finally it is shown that there are obvious differences in occurrence amongst monitoring locations, between spring and autumn, as well as amongst years. However, a clear spatial pattern (e.g. from south to north or from east to west) does not emerge from this (preliminary) analysis. This should be investigated in a statistical model at the end of this project when all data of the entire monitoring period will be available as well. 


\section{Introduction}

\section{$1.1 \quad$ Background}

Observers of coastal bird migration annually report bats flying in from sea (Lagerveld et al. 2014a). Bats have also been observed during ship-based bird surveys in the North Sea and have been found on oil and gas platforms, ships and remote islands (Skiba et al. 2007, Walter et al. 2007, Boshamer \& Bekker 2008, Petersen et al. 2014). So far there have been eight recoveries of Nathusius' pipistrelles (Pipistrellus nathusii) which have shown that bats are able to cross the North Sea successfully. ${ }^{1}$

Several acoustic monitoring studies have been carried out in the North Sea in recent years. Hüppop \& Hill (2016) monitored at the offshore research station FINO 1 in the German territorial Sea from 2004 - 2015 and in the Dutch territorial sea offshore bat activity was monitored at several locations from 2012-2016 (Jonge Poerink et al. 2013, Lagerveld et al. 2014a, 2014b, 2015 \& 2017b).

Currently it is clear that bats occur regularly at the southern North Sea and Nathusius' pipistrelle is the most common species. Most offshore bat activity occurs in the migration season (roughly from late March until late May and from late August until late October) during nights with low to moderate wind speeds. A clear spatial pattern in the occurrence of bats at sea was not proven, but differences in occurrences amongst locations may indicate a spatial pattern (Lagerveld et al 2017b).

If spatial differences of bat occurrence exist at sea it will be important information for wind farms developers and policy makers as bats may become victims of wind turbines due to collisions and barotrauma (Kunz et al. 2007, Baerwald et al. 2008, Bach et al. 2014, Brinkmann et al. 2011, Cryan et al. 2014, Dürr 2013, Jones et al. 2009, Lehnert et al. 2014, Rydell et al. 2010a, b). In order to prevent bats from being killed as well as to prevent downtime of wind turbines due to standstill procedures (mitigation measures) it is beneficial for both ecological and economic reasons to situate wind farms as much as possible outside areas with high(er) densities of bats.

In April 2017 Rijkswaterstaat commissioned a new offshore bat monitoring project as part of the WOZEP program (Offshore Wind Ecological Programme) for ten monitoring locations, extended with three additional locations in 2018. The current monitoring project will continue to at least the end of 2019 and possibly throughout 2020. After that, the final report will be compiled, which will include a spatiotemporal analysis of the offshore occurrence of Nathusius' pipistrelle of all previous monitoring years.

The aim of this report is to:

1. Provide an overview of the monitoring effort and monitoring results in $2017 \& 2018$.

2. Compare the performance of the currently used Avisoft bat detectors (2017-2018) with the previously used Batcorders (2012 - 2016), and assess the correction factor if necessary.

3. Provide a preliminary overview of differences in occurrence amongst the monitoring locations and years as well as differences in the timing of spring and autumn migration of Nathusius' pipistrelle.

\footnotetext{
${ }^{1}$ https://www.bats.org.uk/our-work/national-bat-monitoring-programme/surveys/national-nathusius-pipistrelle-survey
} 


\subsection{Project team}

The project team that conducted this study included: employees of Wageningen Marine Research (WMR; Sander Lagerveld, Bart Noort, Jan Tjalling van der Wal, Pepijn de Vries, Hans Verdaat, Cor Sonneveld and Jaap van der Meer) and the Royal Belgian Institute of Natural Sciences (RBINS; Robin Brabant).

\subsection{Acknowledgements}

In addition to our project sponsor Rijkswaterstaat, other parties provided input and support to our project. We would like to thank in particular Belwind, C-Power, Dana Petroleum, Eneco, Gemini, Neptune Energy, Petrogas E\&P, Venco and Wintershall for facilitating this project by providing monitoring locations, installation and maintenance work and the transfer of monitoring data to shore. This project would never have been possible without their help.

In addition we like to thank Lothar Bach who kindly shared information on the settings of the German offshore Avisoft detectors. 


\section{$2 \quad$ Materials and Methods}

\section{$2.1 \quad$ Study area}

Figure 2-1 shows a map of all offshore and coastal locations where acoustic bat monitoring has been executed in the period 2012 -2018. The operational 2017-2018 monitoring locations can be found in Table 2.1.

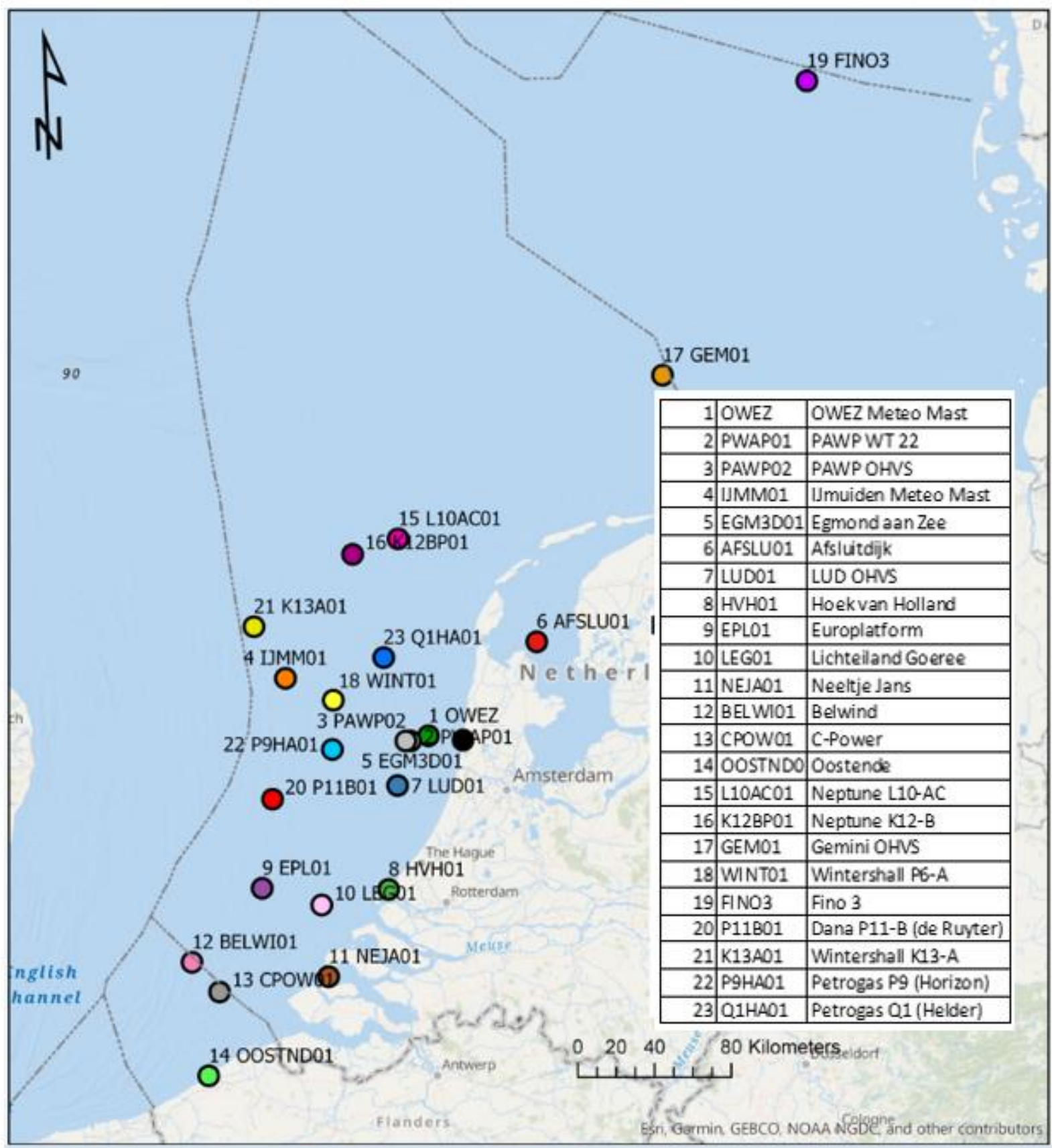

Figure 2-1. Acoustic monitoring network, 2012-2018. See Table 2.1 for the operational 2017-2018 monitoring locations 
Table 2.1 Monitoring locations 2017-2018

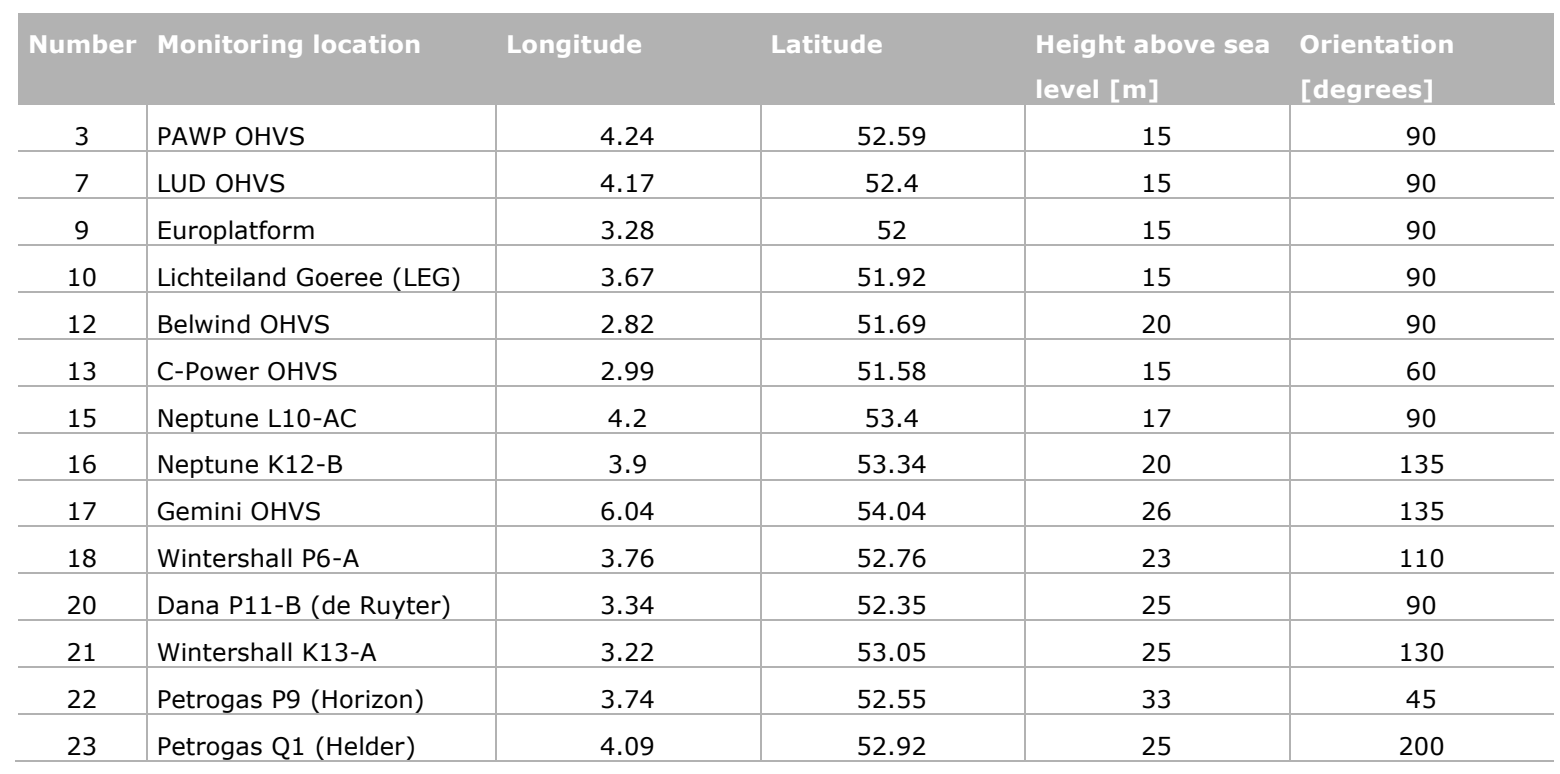

\subsection{Equipment}

Bat activity was monitored with an Avisoft - UltraSoundGate $116 \mathrm{Hnbm}$ in combination with an Electret ultrasound microphone FG-DT50. The microphone was placed in a waterproof box and connected with the soundgate. The performance of the equipment was monitored regularly of the monitoring locations with internet connectivity (PAWP OHVS, LUD OHVS, LEG, Belwind, C-Power, Neptune L10-AC and Neptune K12-B). The microphones were replaced twice a year; late February/early March and late July/early August. Recalibration of the microphones was done by Avisoft Bioacoustics.

We used the same settings as the German Offshore Bat monitoring program (Figure 2.2) in order to be able to pool the Dutch and German data at a later stage. 


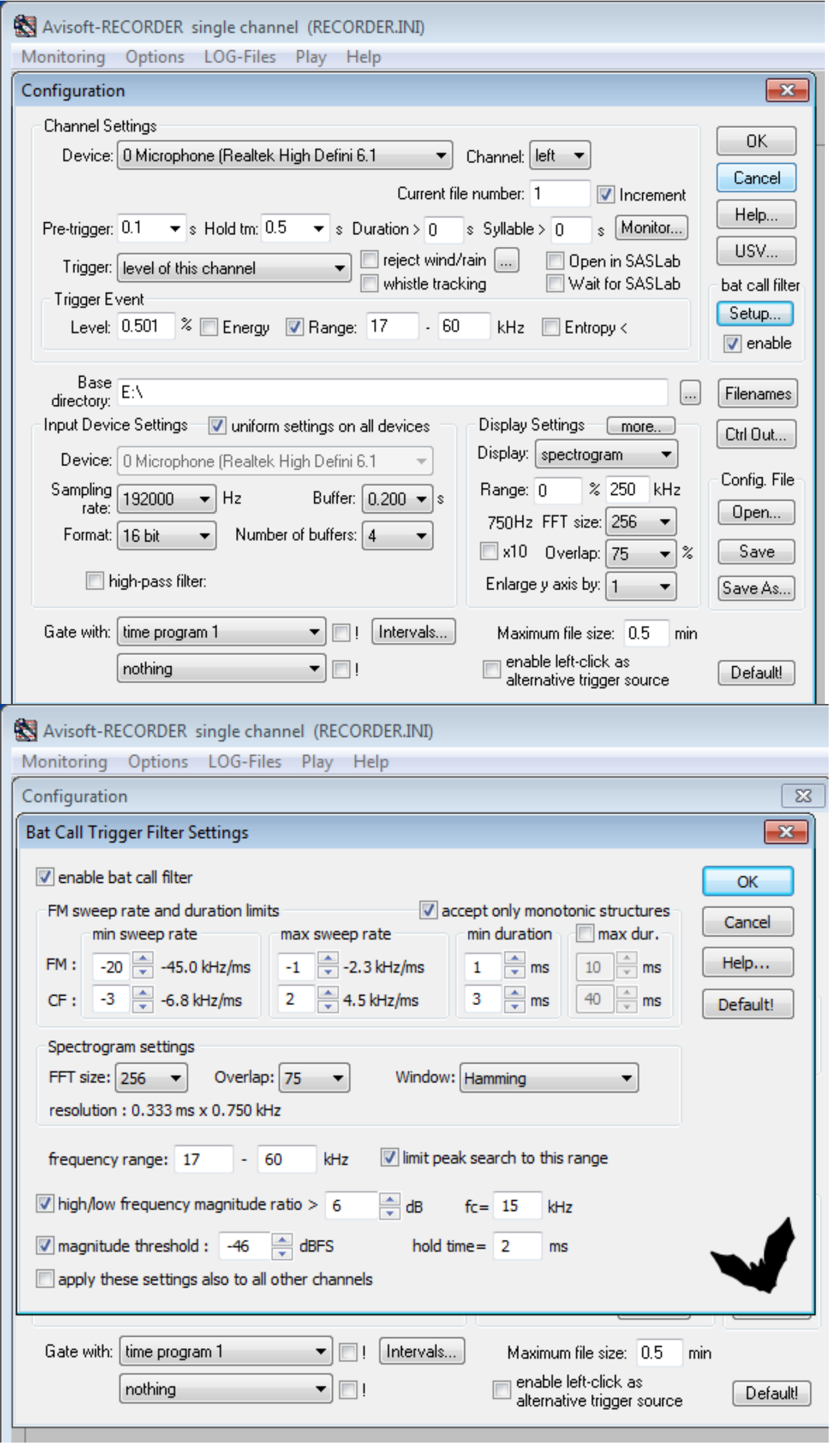

Figure 2.2 Settings of the Avisoft detector 
Previously, from 2012 - 2016, we monitored offshore bat activity with Batcorders. Details on maintenance and settings of the Batcorders can be found in Lagerveld et al (2017b).

In order to compare the performance of Batcorders with the Avisofts, we simultaneously monitored with both detectors at Belwind OHVS, PAWP OHVS and LUD OHVS (Figure 2.3).

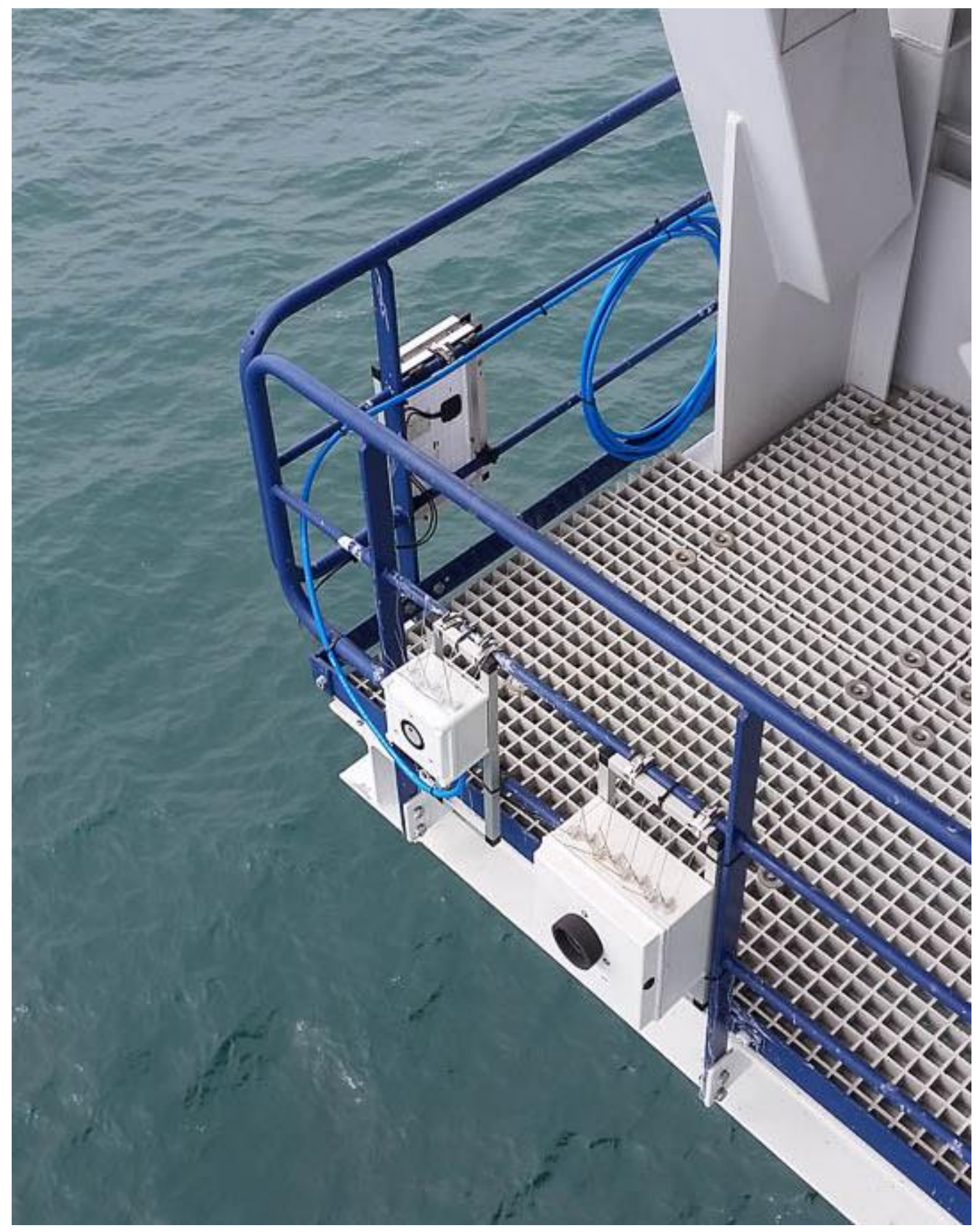

Figure 2.3 Avisoft detector (left) and Batcorder (right) 


\subsection{Data management}

We processed the raw batdetector data to meaningful data (which can be analysed) in five steps:

1. Retrieval of the raw monitoring data to data repository WUR, either online or by data storage.

2. Extraction of recordings with bat calls from the raw monitoring data: from the Avisoft detectors with the SASLab Pro cross-correlation functionality (for details see Lagerveld et al 2017a) and from the Batcorders with BCAdmin 2.0 (for details see Lagerveld et al 2017b).

3. Manual species identification of bat call recordings using the criteria of Barataud (2016).

4. Upload monitoring data (species, date/time, monitoring location, monitoring period, number of pulses) and the various metadata tables (monitoring location, monitoring period, equipment, analist, software) to the WUR Batbase.

5. Extraction of data to be analysed.

\subsection{Analysis}

\subsubsection{Occurrence}

Since bats are nocturnal, it makes more sense to analyse their occurrence per night instead of per calendar day. Therefore we shifted the date limits with 12 hours for the analysis of the data, e.g. 14 April runs from 14 April 12:00 (UTC) until 15 April 12:00 (UTC).

Differences in behaviour (e.g. foraging versus directional flying) may result in huge differences in the number of recorded call sequences, which does not necessarily reflect the relative abundance. An alternative indicator of bat activity which limits (but does not solve) this issue is the presence in a certain time frame, or the ratio between the presence and absence. In this study we use the number of 10 min intervals in which bats have been present as indicator of the relative abundance of bats.

\subsubsection{Comparison performance Avisoft \& Batcorder}

During the periods when monitoring was executed by both an Avisoft and a Batcorder (Table 2.2), we assessed in each time interval whether Nathusius' pipistrelles had been recorded by either detector for different time intervals: 1 minute, 10 minutes, 1 hour, 6 hour and 24 hour intervals. The time on the Batcorders is set manually whereas the Avisofts are PC-based. We noted time-shifts up to two minutes between the Batcorder and the Avisoft and therefore we ignored time differences between individual recordings of two minutes or less during the comparison.

Table 2.2 Overlapping monitoring periods Batcorder \& Avisoft

\begin{tabular}{l|c|c|c} 
Monitoring location & Start & $08-11-2017$ & Number of nights \\
\hline PAWP OHVS & $02-08-2017$ & $03-08-2018$ & 142 \\
\hline PAWP OHVS & $14-03-2018$ & $31-12-2018$ & 138 \\
\hline LUD OHVS & $15-08-2018$ & $26-12-2017$ & 146 \\
\hline Belwind OHVS & $02-08-2017$ & $13-07-2018$ & 116 \\
\hline Belwind OHVS & $19-03-2018$ & $20-12-2018$ & 97 \\
\hline
\end{tabular}

At first the ratio in performance was assessed between de Avisoft and the Batcorder by dividing the recorded number of Avisoft time intervals by the number of Batcorder intervals (for 1 minute, 10 minutes, 1 hour, 6 hour and 24 hour intervals). This ratio was used to make Avisoft monitoring results (better) comparable with Batcorder monitoring results. 
Furthermore we assessed the confidence interval of this ratio for 10 min time intervals. Let $p$ be the probability that a bat (or at least one bat) is recorded in a 10 minute interval, then pA is the conditional probability that it is recorded by the Avisoft detector given that it passes by, and, similarly, pB for the Batcorder. Suppose that these probabilities are independent, then the expected counts are given in Table 2.3.

Table 2.3 Detection options and probabilities

\begin{tabular}{l|c|c} 
Detection options & Symbol & Expected count \\
\hline No bat activity recorded by either detector & $n_{0}$ & $n\left((1-P)+P\left(1-P^{\wedge}\right)\left(1-P^{\wedge}\right)\right)$ \\
\hline Bat activity recorded by the Avisoft & $n_{A}$ & $n\left(\left(P P^{\wedge}\left(1-P^{\wedge}\right)\right)\right.$ \\
\hline Bat activity recorded by the Batcorder & $n_{B}$ & $n\left(P\left(1-P^{\wedge} A\right) P_{B}^{\wedge}\right)$ \\
\hline Bat activity recorded by both detectors & $n_{A B}$ & $n\left(P P^{\wedge} P_{B}^{\wedge}\right)$ \\
\hline
\end{tabular}

Straightforward algebra provides simple estimators for the three probabilities. For example:

$$
\frac{n_{A B}}{n_{B}}=\frac{\hat{p}_{A}}{1-\hat{p}_{A}}
$$

Gives:

$$
\hat{p}_{A}=\frac{n_{A B}}{n_{B}+n_{A B}}
$$

Similarly:

$$
\hat{p}_{B}=\frac{n_{A B}}{n_{A}+n_{A B}}
$$

And:

$$
\hat{p}=\frac{\left(n_{A}+n_{A B}\right)\left(n_{B}+n_{A B}\right)}{n n_{A B}}
$$

The estimated ratio between the two conditional probabilities equals $\hat{p}_{A} / \hat{p}_{B}$. Confidence intervals for this ratio are calculated using the Katz logarithm approach (Gart \& Nam, 1988). This method provides a confidence factor by which the estimated ratio should be divided or multiplied to obtain the confidence interval. The factor is given by

$$
\exp \left(\sqrt[z]{\frac{1-\hat{p}_{A}}{n \hat{p}_{A}}+\frac{1-\hat{p}_{B}}{n \hat{p}_{B}}}\right)
$$

where $z=1.96$ can be used to obtain a 95\% interval, and where $n$ should be interpreted as the number of intervals with bat activity. 


\subsubsection{Differences in abundance and timing}

The earliest Nathusius' pipistrelle in spring/early summer has been recorded on night 11-3-2018 ('Julian' night in year 70, at LEG) and the latest at night 29-6-2015 (Julian 'night' in year 180, at PAWP). The earliest record late summer/autumn has been on night 21-8-2018 (Julian 'night' in year 232, at LEG) and the latest at night 16-11-2018 (Julian 'night' in year 320, at LEG). We therefore consider the variability for spring migration from night in year 70 to 180 and for autumn migration from night in year 232 to 320 .

To assess differences in abundance amongst monitoring locations and differences amongst years we used the average number of 10 min intervals per night for each monitoring location for both seasons in the period 2012-2018. For 2012 - 2016 we used Batcorder data and for 2017 - 2018 we used the data obtained by Avisofts. We adjusted the Batcorder data to make them comparable with the Avisofts (see paragraph 3.3).

To assess differences in timing amongst years we used the median night in year per season. The median date was determined by summing the number of 10 min intervals per night divided by the number of operational locations at that particular monitoring night. After that the median 10 min interval was assessed with the corresponding night in year. For spring migration we considered 2014, 2015, 2016 and 2018 (there was no spring monitoring in 2012 and 2017 and in 2013 the monitoring started late in the season). For autumn migration we considered 2015, 2016, 2017 and 2018 (monitoring ended early in the season in 2012, 2013 and 2014). 


\section{Results}

\subsection{Monitoring effort}

Table 3.1 Effective monitoring effort per location in 2017 and 2018.

\begin{tabular}{|c|c|c|c|c|c|c|c|c|}
\hline & & & 2017 & & & & & \\
\hline Monitoring location & Detector & Date & $\begin{array}{l}\text { Night in } \\
\text { year }\end{array}$ & $\begin{array}{c}\text { Number } \\
\text { of } \\
\text { nights }\end{array}$ & Date & $\begin{array}{l}\text { Night in } \\
\text { year }\end{array}$ & $\begin{array}{c}\text { Number } \\
\text { of } \\
\text { nights }\end{array}$ & Comments \\
\hline PAWP OHVS & Batcorder & $24-7 / 8-11$ & $205-312$ & 107 & $14-3 / 3-8$ & $73-215$ & 142 & \\
\hline PAWP OHVS & Avisoft & $2-8 / 31-12$ & $214-365$ & 151 & $13-1 / 31-12$ & $13-365$ & 352 & \\
\hline LUD OHVS & Batcorder & $17-7 / 30-11$ & $198-334$ & 136 & $1-8 / 31-12$ & $213-365$ & 152 & \\
\hline LUD OHVS & Avisoft & & & & $\begin{array}{c}4-4 / 18-7 \\
\& 15-8 / 31-12\end{array}$ & $\begin{array}{l}94-199 \& \\
227-365\end{array}$ & 243 & \\
\hline Europlatform & Avisoft & & & & $6-3 / 31-12$ & $65-365$ & 300 & \\
\hline Lichteiland Goeree (LEG) & Avisoft & $27-9 / 31-12$ & $270-365$ & 95 & $6-3 / 18-11$ & $65-322$ & 257 & \\
\hline Belwind OHVS & Batcorder & $2-8 / 31-12$ & $214-365$ & 149 & $\begin{array}{c}19-3 / 13-7 \& 14-9 / \\
20-12\end{array}$ & $\begin{array}{c}78-194 \& \\
257-354\end{array}$ & 213 & \\
\hline Belwind OHVS & Avisoft & $2-8 / 26-12$ & $215-360$ & 145 & $1-3 / 31-12$ & $60-365$ & 305 & \\
\hline C-Power OHVS & Avisoft & & & & $28-2 / 31-12$ & $59-365$ & 306 & \\
\hline Neptune L10-AC & Avisoft & $26-7 / 11-12$ & $207-345$ & 138 & $24-1 / 31-12$ & $24-365$ & 341 & \\
\hline Neptune K12-B & Avisoft & $18-8 / 31-12$ & $230-365$ & 135 & $1-1 / 31-12$ & $1-365$ & 365 & \\
\hline Gemini OHVS & Avisoft & & & & $16-3 / 31-12$ & $75-365$ & 290 & \\
\hline Wintershall P6-A & Avisoft & $31-10 / 1-12$ & $304-365$ & 61 & $11-3 / 21-12$ & $70-355$ & 285 & \\
\hline Dana P11-B (de Ruyter) & Avisoft & & & & & & & $\begin{array}{c}\text { from } 2019 \\
\text { onwards }\end{array}$ \\
\hline Wintershall K13-A & Avisoft & & & & - & - & & $\begin{array}{c}\text { no data } \\
\text { (cable error) }\end{array}$ \\
\hline Petrogas P9 (Horizon) & Avisoft & & & & $15-11 / 31-12$ & $319-365$ & 46 & \\
\hline Petrogas Q1 (Helder) & Avisoft & & & & $11-9 / 31-12$ & $254-365$ & 111 & \\
\hline
\end{tabular}

After the start of the project in April 2017 we were able to realise monitoring at PAWP OHVS, LUD OHVS, LEG, Belwind, Neptune L10 AC, Neptune K12 B and Wintershall P6 A the same year. Europlatform, C-Power, Gemini and Wintershall K13 followed early 2018. After the publication of Lagerveld et al. (2017b) Rijkswaterstaat decided to add three monitoring locations to the network, of which Petrogas P9 (Horizon), Petrogas Q1 (Helder) were realised in September and November 2018 respectively and Dana P11-B (de Ruyter) is operational since January 2019. 
We tried to monitor at the predefined locations throughout the entire active season of bats (roughly from mid-March until mid-November), but in some cases downtime occurred due to logistical problems and malfunctioning detectors. In particular it was a pity that we did not obtain data from the Wintershall K13 platform as a result of a defect cable between the Soundgate and the microphone (which was not noted due to the absence of internet connectivity).

The effective monitoring periods per monitoring location are shown in Table 3.1

\subsection{Occurrence of bats per monitoring location}

Figures 3.1 - 3.17 show the occurrence of bats in 10-min intervals per night throughout the monitoring season as recorded by the Avisoft detectors at the various monitoring locations. The time interval between sunset and sunrise is represented by grey. Different species (or species groups) are represented by different colours (Pnat $=$ Nathusius' pipistrelle Pipistrellus nathusii, Ppip = Common pipistrelle Pipistrellus pipistrellus, Nnoc $=$ Common noctule Nyctalus noctula, Nyctaloid $=$ species group, includes genera Nyctalus, Vespertilio, Eptesicus. The actual monitoring period is indicated by a white background, whereas a pink background indicates no monitoring or recorder switched off. At Petrogas P9 (Horizon) no bats were recorded (monitoring started 15 November 2018) and therefore this figure is not shown.

The date/time plots of the Batcorders at Belwind OHVS, PAWP OHVS and LUD OHVS can be found in Annex 1.

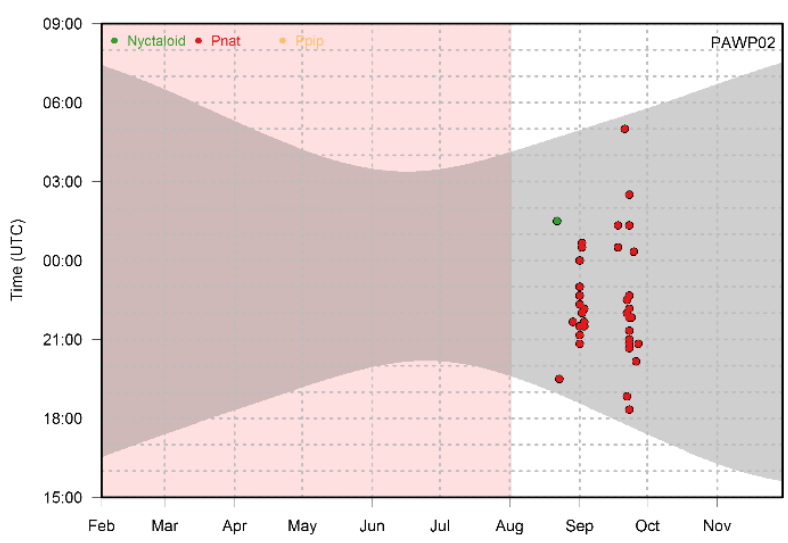

Figure 3.1 Occurrence PAWP OHVS 2017

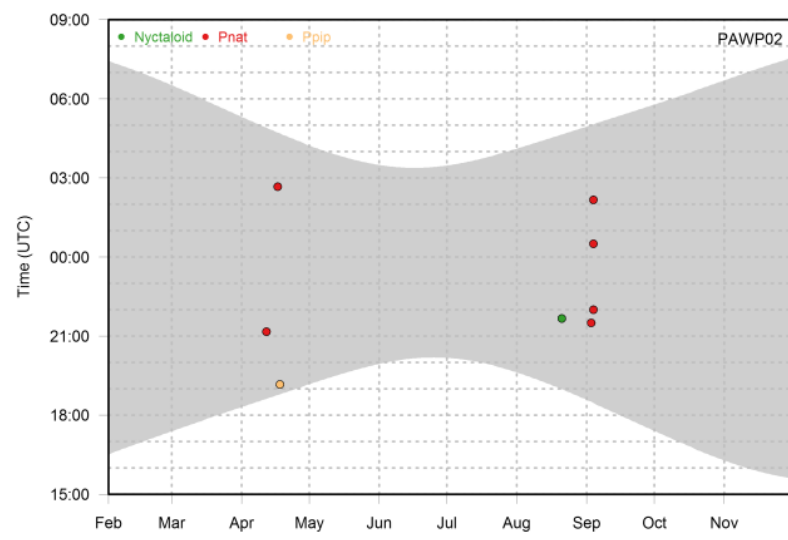

Figure 3.2 Occurrence PAWP OHVS 2018 


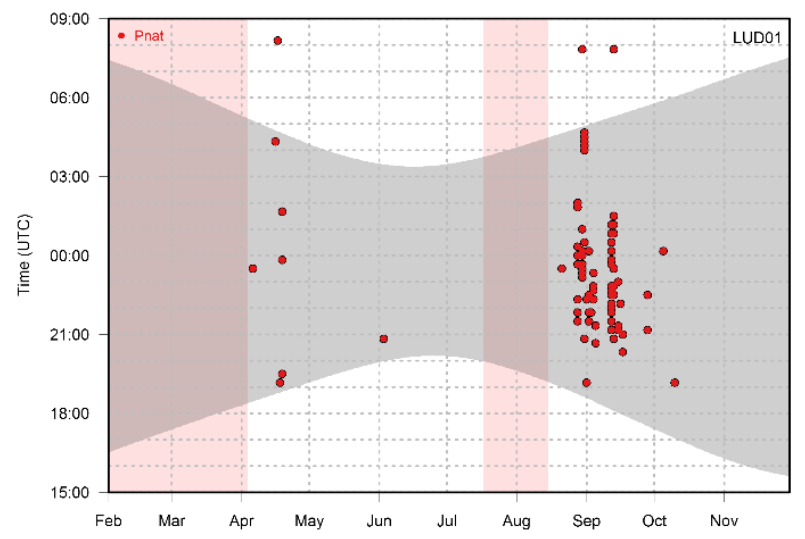

Figure 3. Occurrence LUD OHVS 2018

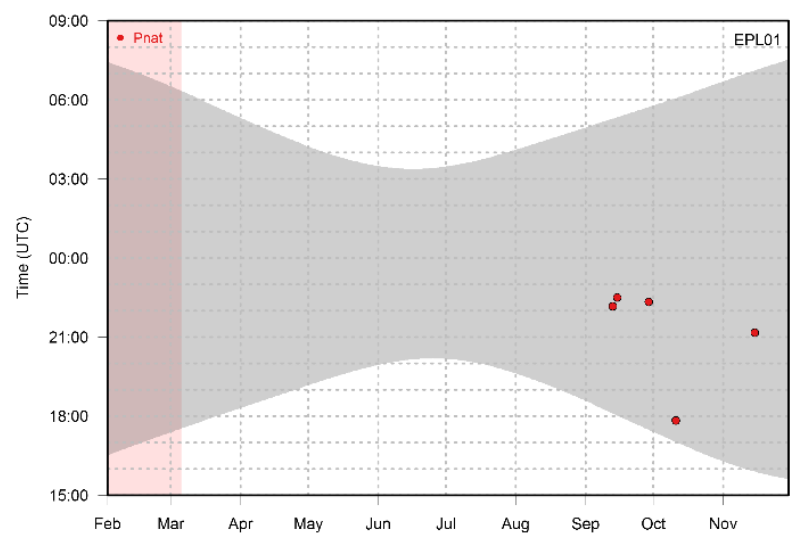

Figure 3.4 Occurrence Europlatform 2018
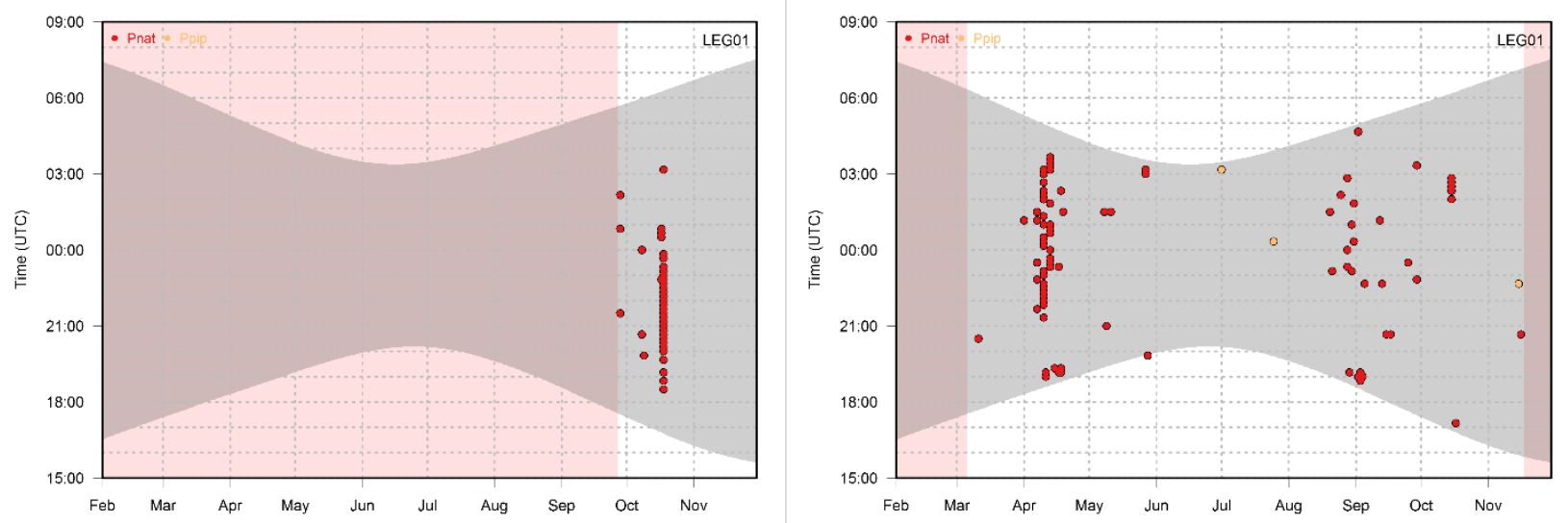

Figure 3.5 Occurrence Lichteiland Goeree 2017

Figure 3.6 Occurrence Lichteiland Goeree 2018
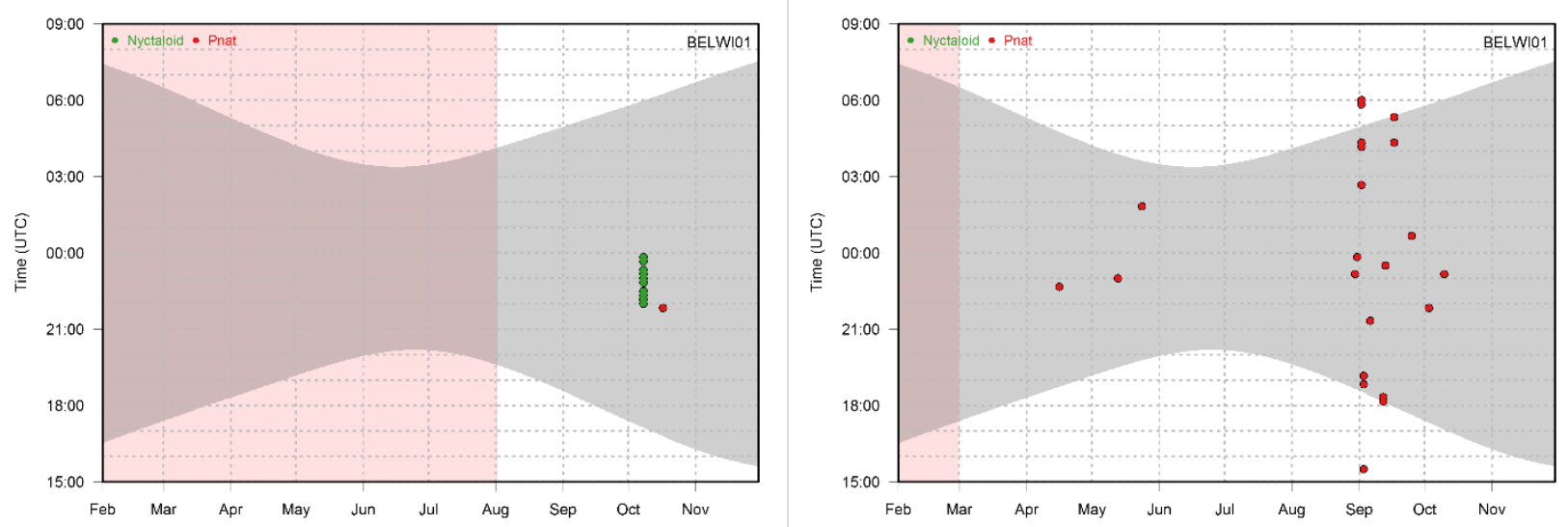

Figure 3.7 Occurrence Belwind 2017

Figure 3.8 Occurrence Belwind 2018 


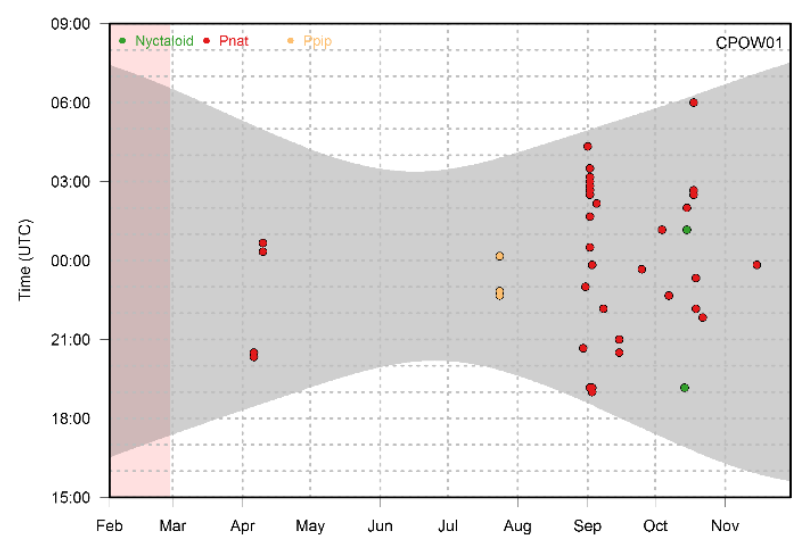

Figure 3.9 Occurrence C-Power 2018
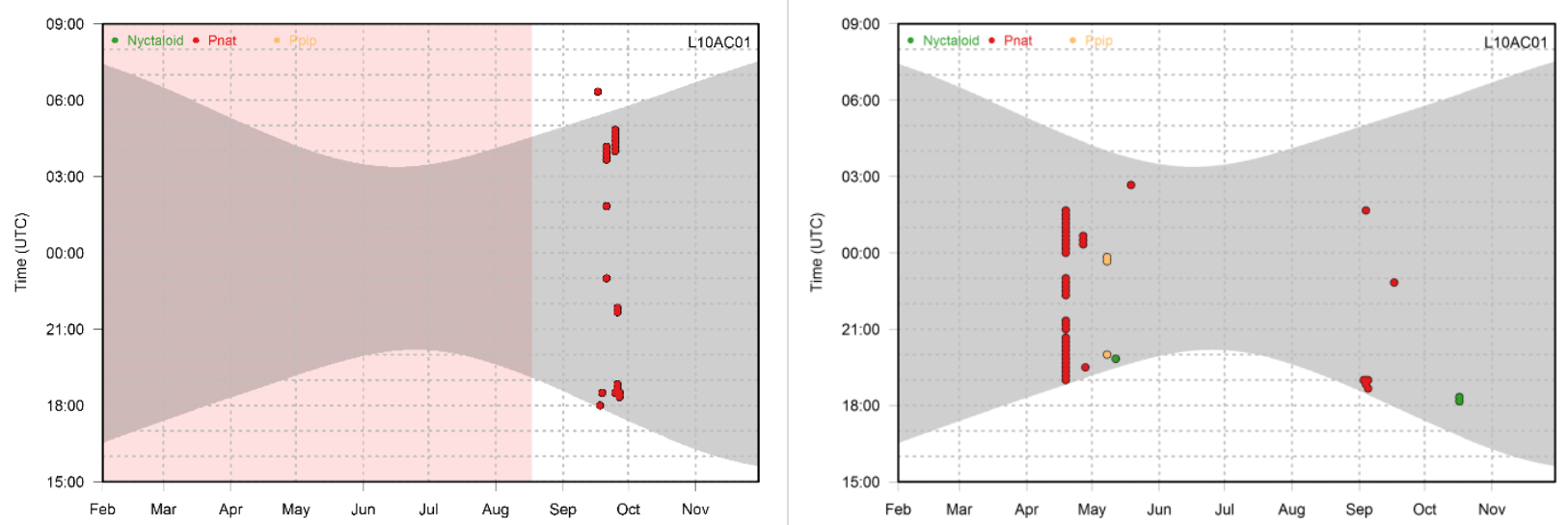

Figure 3.10 Occurrence Neptune L10-AC 2017

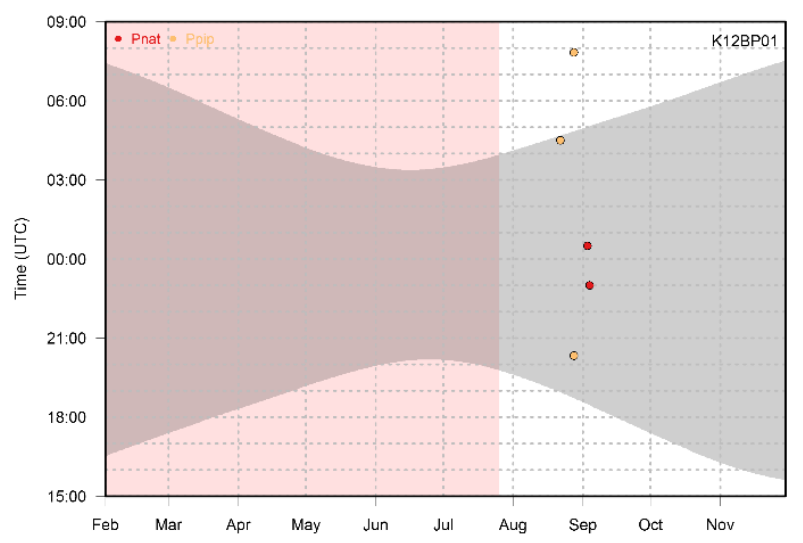

Figure 3.11 Occurrence Neptune L10-AC 2018

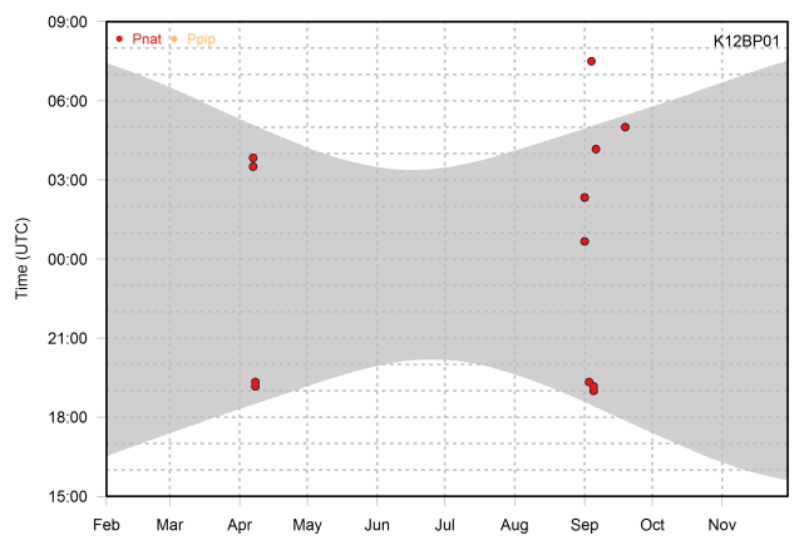

Figure 3.12 Occurrence Neptune K12-BP 2017

Figure 3.13 Occurrence Neptune K12-BP 2018

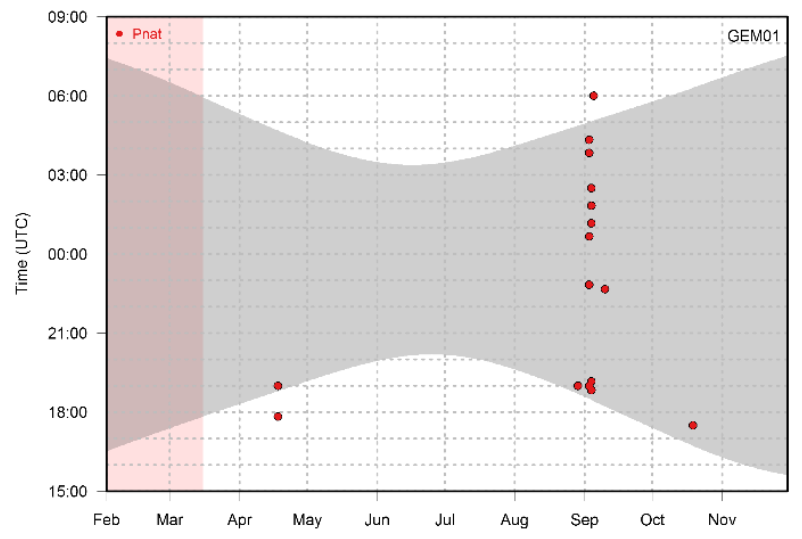

Figure 3.14 Occurrence Gemini 2018 


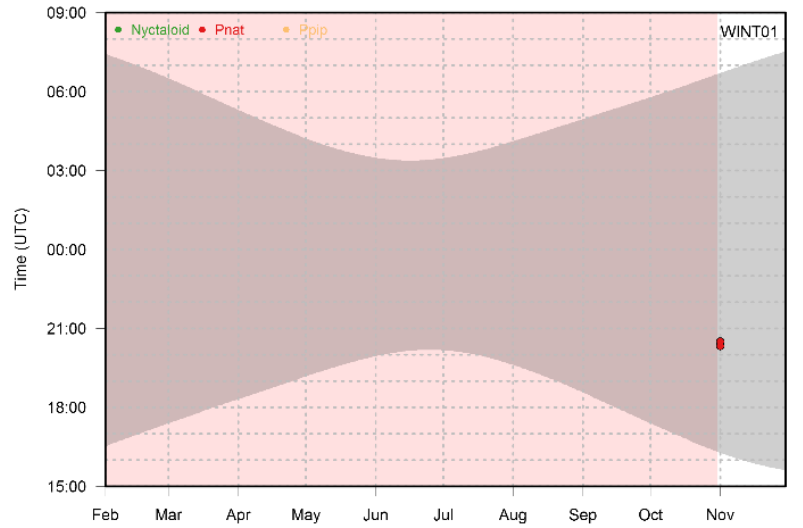

Figure 3.15 Occurrence Wintershall P6-A 2017

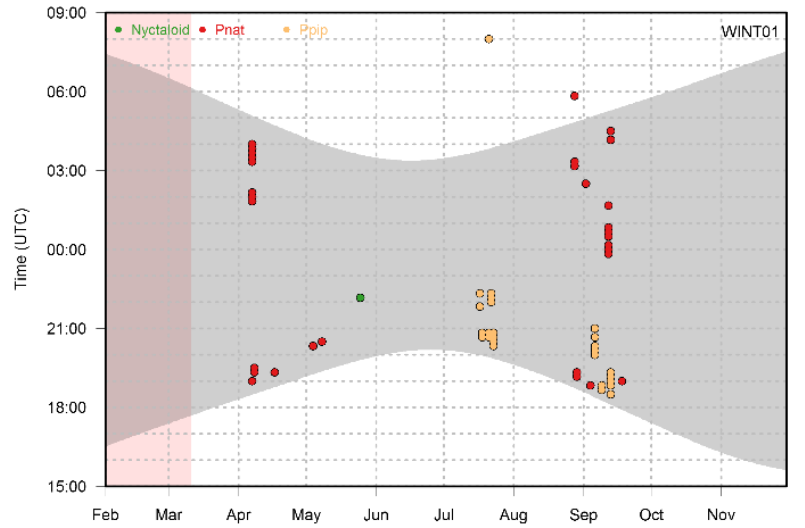

Figure 3.16 Occurrence Wintershall P6-A 2018

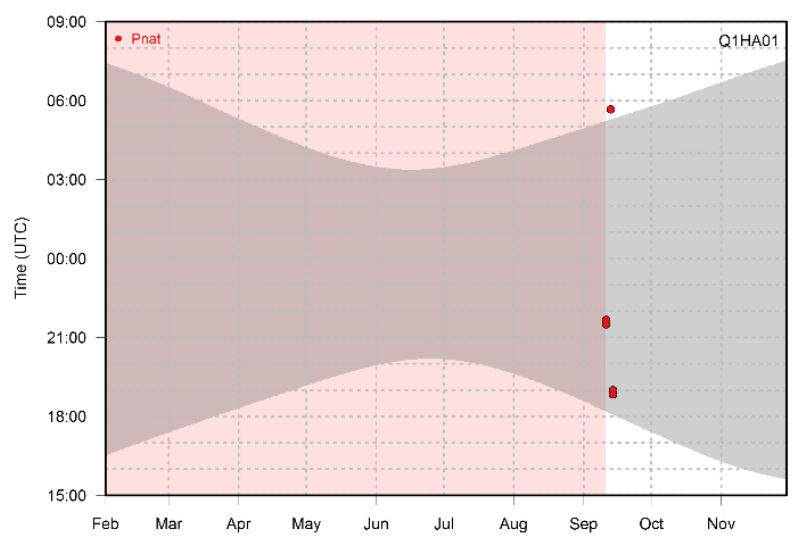

Figure 3.17 Occurrence Petrogas Q1 Helder 2018

\subsection{Comparison Avisoft and Batcorder}

Figure 3.18 shows the differences in performance of the Avisoft and the Batcorder based on the detection of Nathusius' pipistrelle in different time intervals: 1 minute, 10 minutes, 1 hour, 6 hour and 24 hour intervals. It is obvious that the Avisoft records bat calls in more intervals than the Batcorder but differences become smaller when the time interval increases. 


\begin{tabular}{|c|c|c|}
\hline \multicolumn{3}{|c|}{1 minute intervals } \\
\hline Overlap & 84 & \\
\hline Avisoft total & 143 & \\
\hline Batcorder total & 95 & \\
\hline \multicolumn{3}{|c|}{ Ratio Avisoft / Batcorder = $151 \%$} \\
\hline \multicolumn{3}{|c|}{10 minute intervals } \\
\hline Overlap & 67 & \\
\hline Avisoft total & 118 & \\
\hline Batcorder total & 77 & \\
\hline \multicolumn{3}{|c|}{ Ratio Avisoft / Batcorder $=153 \%$} \\
\hline \multicolumn{3}{|c|}{1 hour intervals } \\
\hline Overlap & 54 & \\
\hline Avisoft total & 84 & \\
\hline Batcorder total & 62 & \\
\hline \multicolumn{3}{|c|}{ Ratio Avisoft / Batcorder $=135 \%$} \\
\hline \multicolumn{3}{|c|}{6 hour intervals } \\
\hline Overlap & 37 & \\
\hline Avisoft total & 54 & \\
\hline Batcorder total & 43 & \\
\hline \multicolumn{3}{|c|}{ Ratio Avisoft / Batcorder $=126 \%$} \\
\hline \multicolumn{3}{|c|}{24 hour intervals } \\
\hline Overlap & 31 & \\
\hline Avisoft total & 42 & \\
\hline Batcorder total & 36 & \\
\hline Ratio Avisoft / B & 3atcorder $=117 \%$ & - Both detectors = Avisoft only at Batcorder only \\
\hline
\end{tabular}

Figure 3.18 Comparison of the performance of the Avisoft detector and Batcorder in different time intervals. 
The observed counts for 10 minute intervals is shown in table 3.2

Table 3.2 Detection options and observed counts

\begin{tabular}{l|c|c} 
Monitoring location & Symbol & $\mathrm{n}_{0}$ \\
\hline No bat activity recorded by either detector & $\mathrm{n}_{\mathrm{A}}$ & 79468 \\
\hline Bat activity recorded by the Avisoft & $\mathrm{n}_{\mathrm{B}}$ & 51 \\
\hline Bat activity recorded by the Batcorder & $\mathrm{n}_{\mathrm{AB}}$ & 10 \\
\hline Bat activity recorded by both detectors & 67
\end{tabular}

The total number of 10 min intervals with bat activity is therefore $10+51+67=128$. Applying the formulas $1-4$ it is predicted that bat activity occurred in $n=136$ time intervals ( 8 more intervals than observed). The estimated ratio between the two conditional probabilities ( $\hat{p}_{\mathrm{A}} / \hat{p}_{\mathrm{B}}$ ) equals 1.53. Applying the Katz logarithm approach (formula 5 ) and using $n=136$ results in a value of the estimated confidence interval of 1.17 , which means that the ratio lies between 1.31 and 1.79 .

In order to obtain a confidence interval of 1.1 the number of 10 minute intervals with bat activity should be increased to approximately 400 and a confidence interval of 1.05 can be achieved with 1250 intervals with bat activity.

\subsection{Variability amongst monitoring locations and years}

To show the occurrence of bats at each monitoring location the occurrence was expressed as the number of 10 min intervals per night per location. In order to make Batcorder monitoring data comparable with Avisoft monitoring data we applied a correction factor for the Batcorder data (1.53 for 10 minute intervals, see paragraph 3.3). Note that monitoring periods amongst the various locations may differ (Annex 2).

In spring the average for all years for all monitoring locations combined is $0.08+/-0.02(10 \mathrm{~min})$ time intervals per night per location, but differences amongst years and locations are substantial (figure 3.19). 
1.2

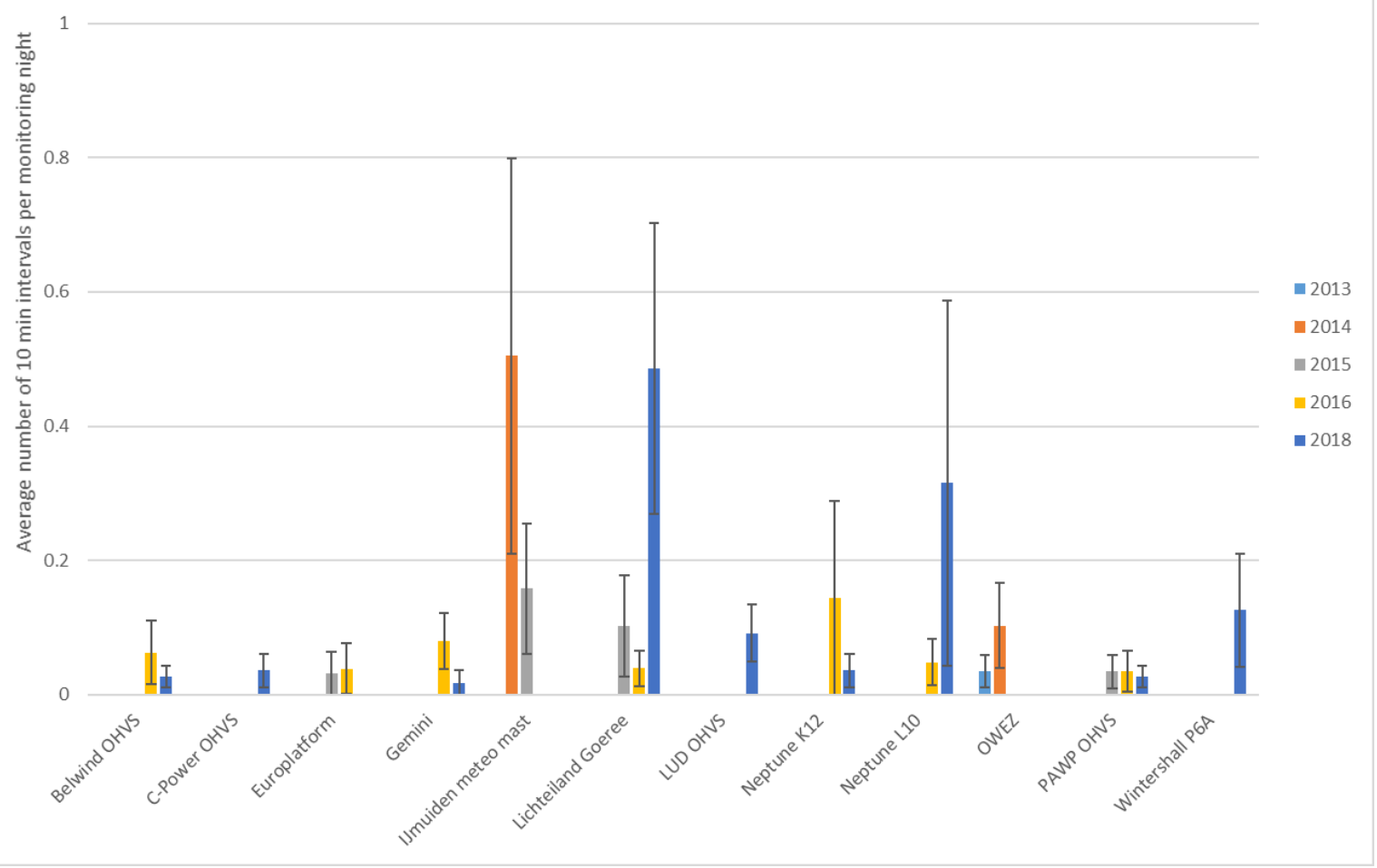

Figure 3.19 The average number of 10 min intervals with Nathusius' pipistrelle per night per monitoring location for different years in spring, including standard error. 
In autumn the average for all years for all monitoring locations combined is $0.30+/-0.05$ (10 min) time intervals per night per location, but also here there are significant differences amongst years and locations (figure 3.20).

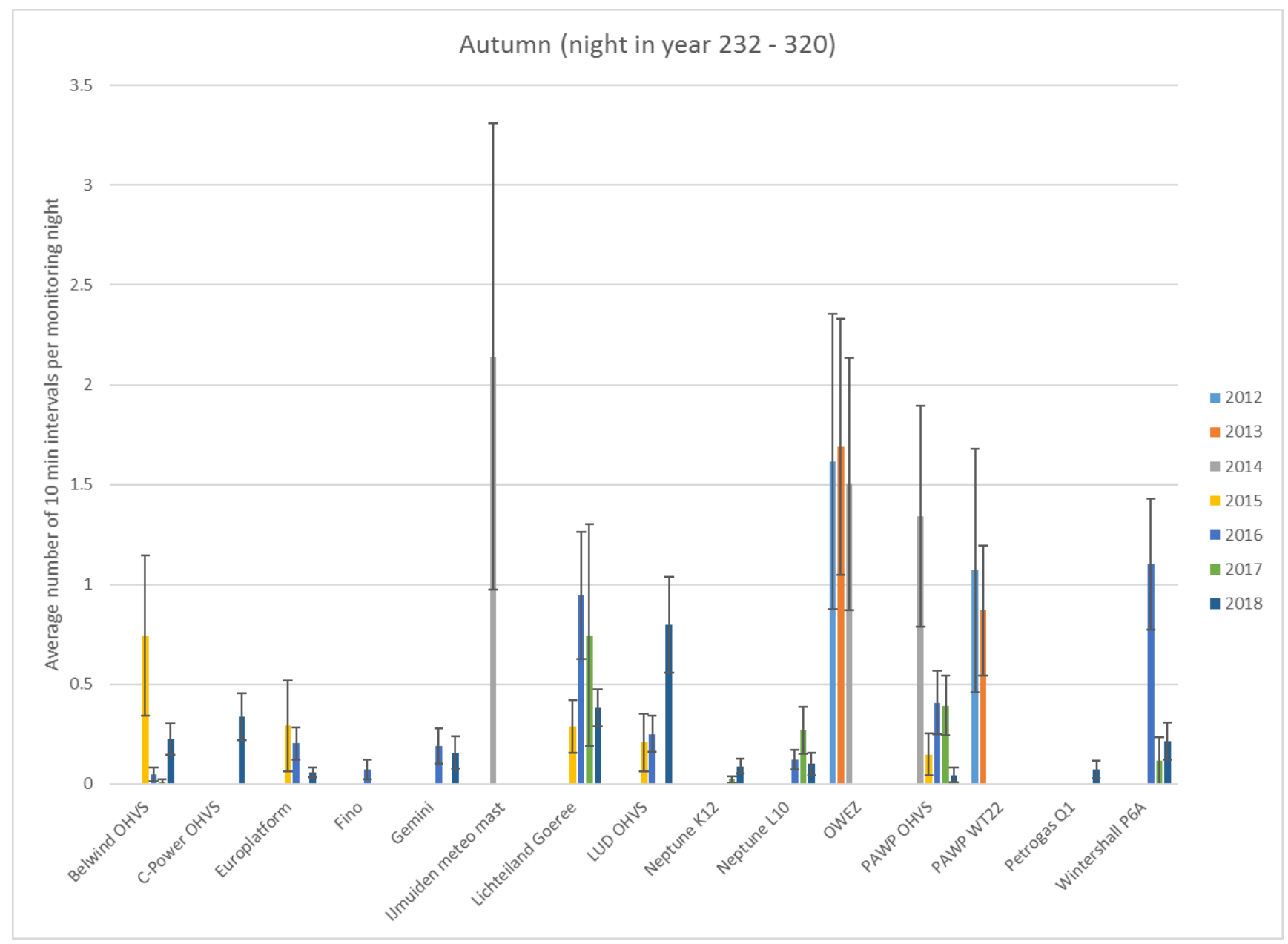

Figure 3.20 The average number of 10 min intervals with Nathusius' pipistrelle per night per monitoring location for different years in autumn, including standard error.

\subsection{Variability in timing}

Figures 3.21 - 3. 32 show the average number of 10 min intervals with Nathusius' pipistrelle per monitoring location per night for spring (night in year 70 - 180) and autumn (night in year 232 320). Note the different scales in spring and autumn.

Both in spring and autumn the occurrence does not only differ in numbers but also in timing, with peaks occurring at different moments in the season 


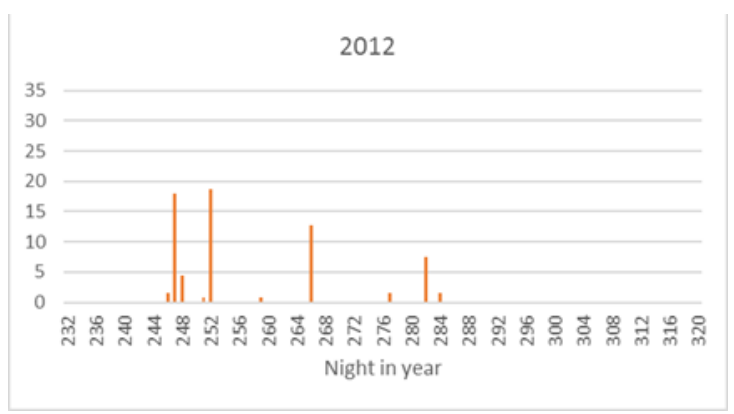

Figure 3.21 Average number of 10 min intervals with bats per monitoring location $(n=2)$ per monitoring night $(n=73)$ Autumn 2012

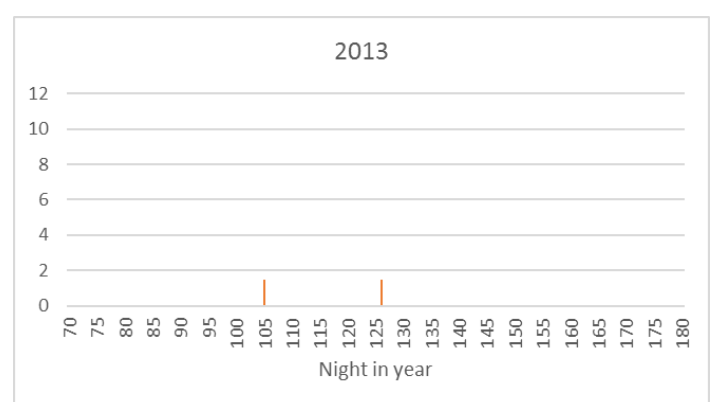

Figure 3.22 Average number of 10 min intervals with bats per monitoring location $(n=1)$ per monitoring night $(n=87)$ Spring 2013

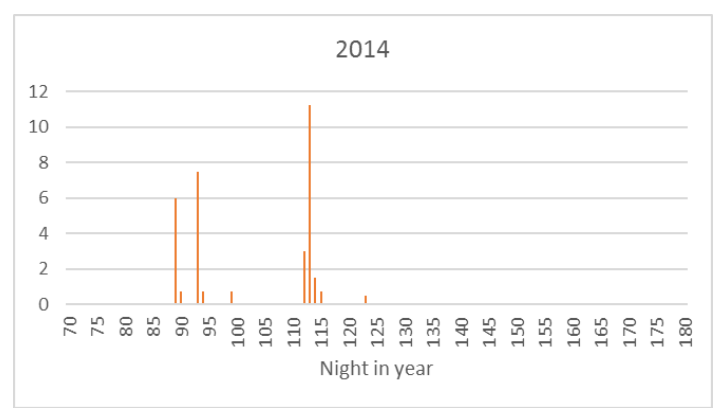

Figure 3.24 Average number of 10 min intervals with bats per monitoring location $(n=3)$ per monitoring night $(n=257)$ Spring 2014

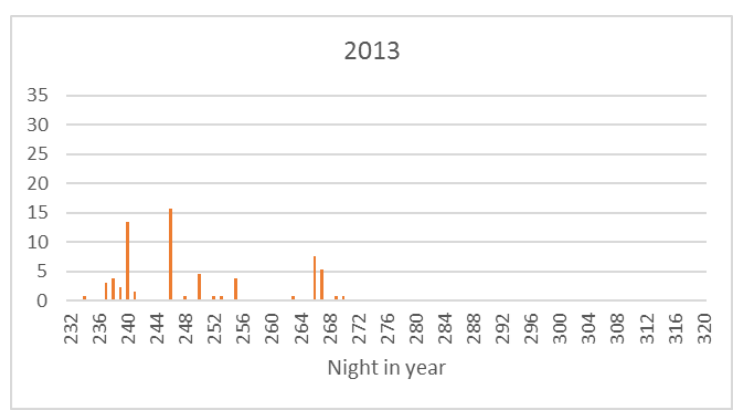

Figure 3.23 Average number of 10 min intervals with bats per monitoring location $(n=2)$ per monitoring night ( $n=101)$ Autumn 2013

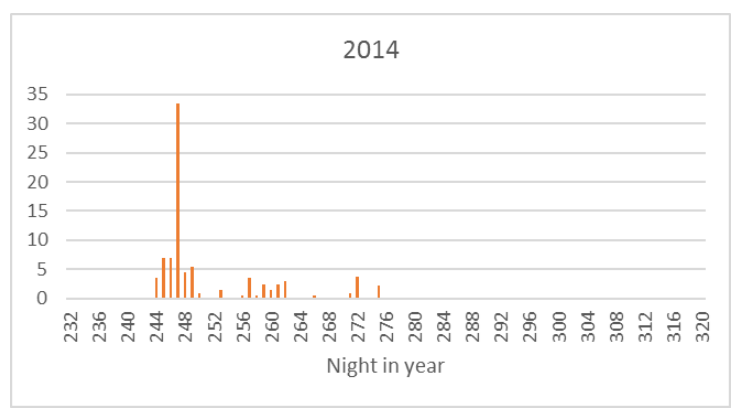

Figure 3.25 Average number of 10 min intervals with bats per monitoring location $(n=3)$ per monitoring night $(n=153)$ Autumn 2014 


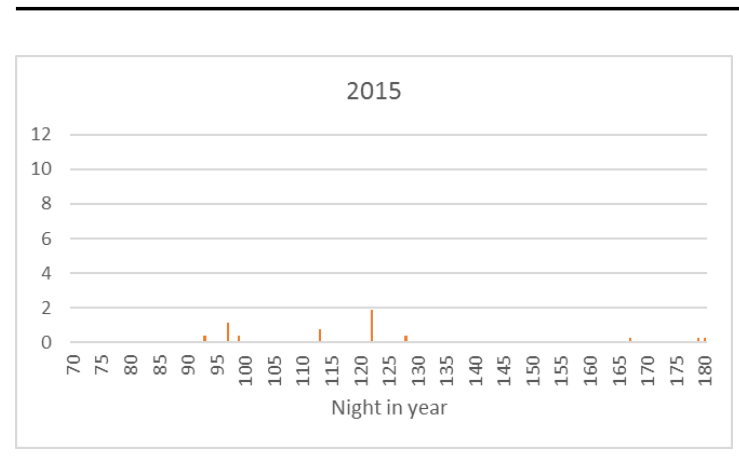

Figure 3.26 Average number of 10 min intervals with bats per monitoring location $(n=5)$ per monitoring night ( $n=437)$ Spring 2015

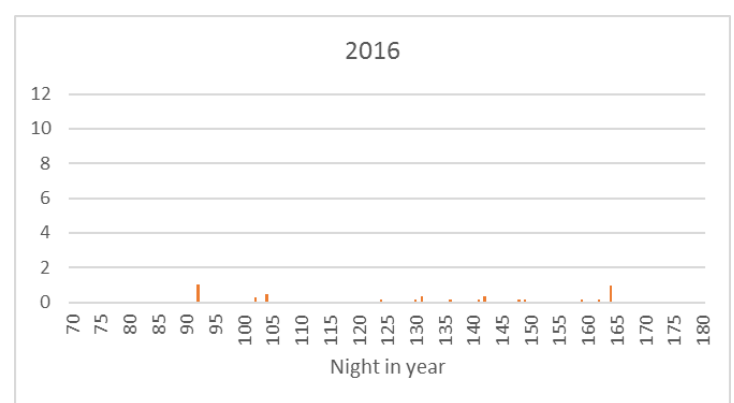

Figure 3.28 Average number of 10 min intervals with bats per monitoring location $(n=8)$ per monitoring night ( $n=658)$ Autumn 2016

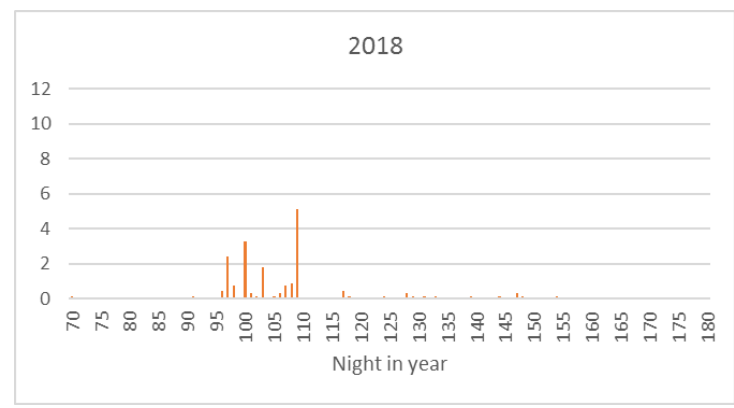

Figure 3.31 Average number of 10 min intervals with bats per monitoring location $(n=10)$ per monitoring night $(n=1086)$ Autumn 2012

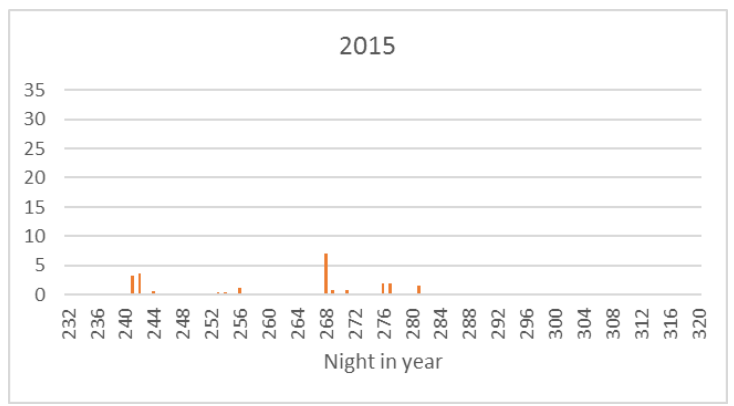

Figure 3.27 Average number of 10 min intervals with bats per monitoring location $(n=5)$ per monitoring night $(n=274)$ Autumn 2015

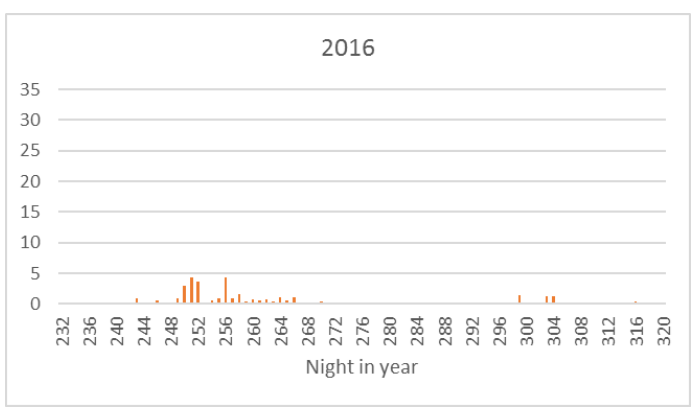

Figure 3.29 Average number of 10 min intervals with bats per monitoring location $(n=9)$ per monitoring night $(n=656)$ Autumn 2016

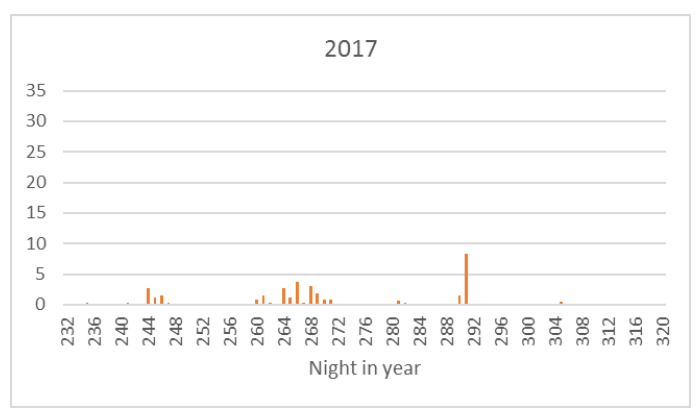

Figure 3.30 Average number of 10 min intervals with bats per monitoring location $(n=6)$ per monitoring night $(n=424)$ Autumn 2017

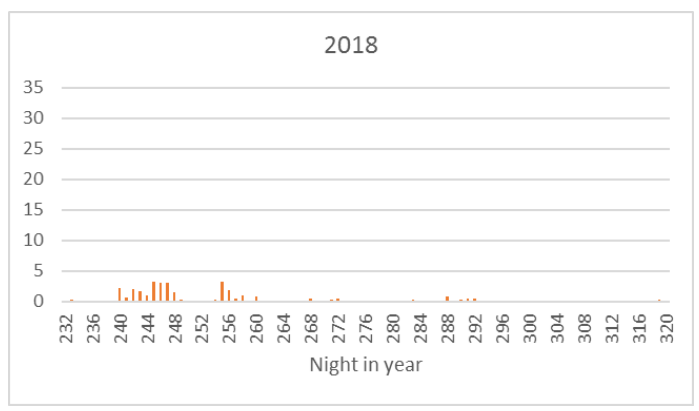

Figure 3.32 Average number of 10 min intervals with bats per monitoring location $(n=12)$ per monitoring night $(n=958)$ Autumn 2018 
Table 3.4. and Table 3.5 show the monitoring period per year (when at least one monitoring location has been operational) as well as the first, median and last occurrence. In some cases this could not be assessed due to lacking data (spring \& autumn 2012 and spring 2017), or a late start/early end of the monitoring (spring 2013 and autumn 2013 \& 2014). 
Table 3.4 Night in year when monitoring started/ended and first, median and last occurrence in spring for different years and the average for all years.

\begin{tabular}{c|c|c|c|c|c}
\multicolumn{2}{c}{} & \multicolumn{2}{c}{ Monitoring } & \multicolumn{2}{c}{ Occurrence } \\
Year & Start & End & - & Median & Last \\
\hline 2012 & - & - & - & - & 126 \\
\hline 2013 & 94 & 180 & 90 & 112 & 123 \\
\hline 2014 & 65 & 180 & 93 & 122 & 180 \\
\hline 2015 & 61 & 180 & 92 & 131 & 164 \\
\hline 2016 & 76 & 180 & - & - & - \\
\hline 2017 & - & 180 & 70 & 105 & 154 \\
\hline 2018 & 1 & 180 & 86 & 118 & 149 \\
\hline Average & 59 & & & & \\
\hline
\end{tabular}

The average median date in spring is night in year 118 but the median date seems to be very variable. In 2018 it occurred much earlier in the season (night in year 105) and in 2016 much later (night in year 131), a difference of 26 days.

Table 3.5 Night in year when monitoring started/ended and first, median and last occurrence in autumn for different years and the average for all years.

\begin{tabular}{c|c|c|c|c|c}
\multicolumn{2}{c}{} & \multicolumn{2}{c}{ Monitoring } & Focurrence & Median \\
Year & Start & End & - & - & - \\
\hline 2012 & 242 & 294 & 234 & - & - \\
\hline 2013 & 181 & 288 & 244 & - & - \\
\hline 2014 & 181 & 287 & 241 & 268 & 281 \\
\hline 2015 & 181 & 309 & 242 & 256 & 316 \\
\hline 2016 & 181 & 321 & 235 & 268 & 305 \\
\hline 2017 & 181 & 365 & 232 & 247 & 320 \\
\hline 2018 & 181 & 365 & 238 & 260 & 306 \\
\hline Average & 190 & 318 & & & \\
\hline
\end{tabular}

In autumn the average median date is night in year 260. Also here the median date varies amongst years. In 2018 it occurred much earlier in the season (night in year 247) and in 2015 and 2017 later (night in year 268), a difference of 21 days. 


\section{$4 \quad$ Discussion and conclusions}

\subsection{Monitoring results 2017 / 2018}

Two species of bat were recorded during 2017/2018; Nathusius' pipistrelle (Pipistrellus nathusii) and Common pipistrelle (Pipistrellus pipistrellus). Some recordings could not be identified to species level and were classified as the species group Nyctaloid (includes genera Nyctalus, Vespertilio, Eptesicus).

Nathusius' pipistrelle was the most common recorded bat at sea. Spring migration peaked in April and autumn migration peaked in September. Common pipistrelle was much more scarce with a few records in spring and autumn. Noteworthy were the occurrences in July 2018 at LEG, C-Power and Wintershall P6-A. Nyctaloids were uncommon in general with a few scattered records in May, August and October.

Therefore, the offshore occurrence of bats during 2017/2018 matches the general pattern of occurrence in previous years (Jonge Poerink et al. 2013, Lagerveld et al. 2014a, 2014b, 2015 \& 2017b).

\subsection{Acoustic monitoring with Avisoft and Batcorder}

Monitoring results can be influenced by the type of detector in combination with the settings of the detector and the application of different software for the extraction of bat calls from the raw monitoring data. Simultaneous monitoring by an Avisoft detector and a Batcorder indicated a much better performance of the Avisoft. This corresponds with the findings of Adams et al. (2012) which evaluated the performance of several types of batdetectors, including Avisoft and Batcorder. In order to make monitoring results comparable a correction factor should be applied, the ratio between Avisoft and Batcorder detections. The value of this factor depends on the time interval used in the analysis (Paragraph 3.3).

The Avisoft / Batcorder ratio of 10 minute intervals with bat activity was estimated at 1.53 with a confidence interval of 1.17 (bandwidth 1.31 - 1.79). In order to make this parameter more precise more data must be gathered. At this moment there are four monitoring locations with both an Avisoft and a Batcorder (Belwind OHVS, C-power OHVS, LUD OHVS and PAWP OHVS) and previous monitoring results (Lagerveld et al. 2015 \& 2017b) show that these locations should produce around 125 (10 minute) time intervals in total annually. A continuation of the monitoring for two years will therefore result in a total number of around 380 intervals and a corresponding confidence interval of approximately 1.1 . If a confidence interval of 1.05 should be achieved simultaneous monitoring at these four locations should continue for approximately nine years, in order to reach 1250 intervals. 


\subsection{Variation in time and in space}

There is an obvious difference in relative abundance of Nathusius' pipistrelles between spring and autumn. In spring the average per year for all monitoring locations combined is 0.08 (10 minute intervals of bat presence per night per monitoring location), whereas in autumn the overall average is 0.30 (a factor 4 higher). This seasonal difference may be caused by an increased population in autumn (juveniles), but also by more foraging activity due to a higher insect availability at sea (Teunissen \& Veling 2013). Another possibility may be that bats use different routes in spring and autumn, migrate at higher altitudes in spring, or apply different seasonal stopover behaviour as is common in migrant birds (See Berthold, 1990 and Newton 2008 for a review).

The relative abundance seems also to vary amongst years, both in spring and in autumn. In spring the average abundance (for all monitoring locations combined) ranges from 0.04 in 2013 to 0.29 in 2014 (a factor 7 difference). In autumn differences range from 0.26 in 2017 to 1.52 in 2014 (a factor 6 difference). These observed differences are in some extent caused by different monitoring periods amongst years and a varying number of monitoring locations (Annex 2). For example in 2014 there were only three operational monitoring locations which all had good numbers of bats that year and were mainly operational during peak migration periods. However, this is not the only cause as there are also marked differences amongst years at the same monitoring locations with similar monitoring periods, e.g. Lichteiland Goeree in spring and autumn, as well as PAWP OHVS in autumn (Annex 2 and figures $3.19 \& 3.20$ ). However there are also monitoring locations which appear to receive a more stable number of seasonal bats (e.g. OWEZ in autumn, figure 3.20).

Differences in abundance amongst years may reflect actual fluctuations in numbers, for example due to differences in mortality or reproduction success, but may also be caused by following different migration routes or stopover behaviour, e.g. as a result of weather conditions along the way. From the study by Lagerveld et al (2017b) it is clear that in particular low to moderate tailwind conditions trigger migration over sea. This weather dependency may well be a cause for differences in timing amongst years. We found a substantial variance in timing of migration amongst years; a difference up to 26 days of the median date of occurrence amongst years in spring and a difference of 21 days in autumn.

A clear spatial pattern (e.g. from south to north or from east to west) does not emerge from this (preliminary) analysis. This should be investigated in a statistical model at the end of this project when the 2019 -and possibly the 2020- data will be available as well. Note that the geographical scope of this spatial analysis will be the Dutch and Belgian territorial sea roughly between Ostend and Texel. As there is only one operational monitoring location north of the Wadden Islands (Gemini) it is currently not possible to include other areas of the southern North Sea in the spatial analysis. 


\section{Quality Assurance}

Wageningen Marine Research utilises an ISO 9001:2015 certified quality management system. This certificate is valid until 15 December 2021. The organisation has been certified since 27 February 2001. The certification was issued by DNV GL. 


\section{References}

Adams A., Jantzen M., Hamilton R. \& Fenton, M. 2012. Do you hear what I hear? Implications of detector selection for acoustic monitoring of bats. Methods in Ecology and Evolution, 3(6), 992-998.

Bach P., Bach L. \& Ekschmitt K. 2014. Bat activities and bat fatalities at different windfarms in NorthwestGermany. Book of Abstracts XIIIth European Bat Research Symposium, Sibenik, Croatia.

Baerwald, E.F., D'Amours G.H., Klug B.J., Barclay R.M.R. 2008. Barotrauma is a significant cause of bat fatalities at wind turbines. Current Biology 18: 695-696.

Barataud M. 2015. Acoustic ecology of European bats. Species, identification, study of their habitats and foraging behaviour. Biotope, Mèze; Meséum nationale d'Histoire naturelle (Inventaires et biodiversité series), Paris, France.

Berthold P, 1990. VOgelzug - eine kurze, aktuelle Gesamtübersicht. Wissensschaftliche Buchgesellschaft, Darmstadt

Boshamer J.P.C. \& Bekker J.P. 2008. Nathusius' pipistrelles (Pipistrellus nathusii) and other species of bats on offshore platforms in the Dutch sector of the North Sea. Lutra 51: 17-36.

Brinkmann R., Behr O., Niermann I. \& Reich M. 2011. Entwicklung von Methoden zur Untersuchung und Reduktion des Kollisionsrisikos von Fledermäusen an Onshore-Windenergieanlagen, Volume 4 Umwelt und Raum. Cuvillier Verlag, Göttingen.

Cryan P.M., Gorresen P.M., Hein C.D., Schirmacher M.R., Diehl R.H., Huso M.M., Hayman D.T.S., Fricker P.D., Bonaccorso F.J., Johnson D.H., Heist K. \& Dalton D.C. 2014. Behavior of bats at wind turbines. www.pnas.org/cgi/doi/10.1073/pnas.1406672111.

Dürr T. 2013. Fledermausverluste an Windenergieanlagen. Daten aus der zentralen Fundkartei der Staatlichen Vogelschutzwarte im Landesumweltamt Brandenburg. Stand 25.09..2013.

www.mluv.brandenburg.de/cms/ media.php /.../wka_fmaus.xls.

Gart, J.J. and Nam, J. (1988) Approximate Interval Estimation of the Ratio of Binomial Parameters: A Review and Corrections for Skewness. Biomet-rics, Volume 44, 323-338.

Hüppop O. \& Hill R. 2016. Migration phenology and behaviour of bats at a research platform in the south-eastern North Sea/ Lutra 59 (1-2): 5-22

Jonge Poerink B., Lagerveld S. \& Verdaat H. 2013. Pilot study Bat activity in the Dutch offshore wind farms OWEZ and PAWP 2013). IMARES report C026/13.

Kunz, T. H., Arnett, E. B., Erickson, W. P., Hoar, A. R., Johnson, G. D., Larkin, R. P., Strickland, M. D., Thresher, R. W. and Tuttle, M. D. (2007), Ecological impacts of wind energy development on bats: questions, research needs, and hypotheses. Frontiers in Ecology and the Environment, 5: 315324.

Lagerveld S., Jonge Poerink B. \& Verdaat H. 2014a. Monitoring bat activity in offshore windfarms OWEZ and PAWP in 2013. IMARES rapport C165/14.

Lagerveld, S., B.J. Poerink, R. Haselager \& H. Verdaat 2014b. Bats in Dutch offshore wind farms in autumn 2012. Lutra 57: 61-69. 
Lagerveld, S., Jonge Poerink B., Vries P. de 2015. Monitoring bat activity at the Dutch EEZ in 2014. Den Helder, IMARES, (Report / IMARES Wageningen UR C094/15).

Lagerveld S., Kooistra G., Otten G., Meesters L., Manshanden J., de Haan D., Gerla D., Verhoef H. \& Scholl M. 2017a. Bat flight analysis around wind turbines - a feasibility study; Wageningen, Wageningen Marine Research (University \& Research Centre), Wageningen Marine Research report C026/17. $40 \mathrm{p}$

Lagerveld S., Gerla D., van der Wal J.T., de Vries P., Brabant R., Stienen E., Deneudt K., Manshanden J. \& Scholl M. 2017b. Spatial and temporal occurrence of bats in the southern North Sea area. Wageningen Marine Research (University \& Research centre), Wageningen Marine Research report C090/17; 52 p.

Lehnert L.S., Kramer-Schadt S., Schönborn S., Lindecke O., Niermann I. \& Voigt C.C. 2014. Windfarm facilities in Germany kill Noctule bats from near and far. PLoS ONE 9(8): e103106.

doi:10.1371/journal.pone.0103106.

Newton I, 2008. The migration ecology of birds. Academic Press

Petersen A., Jensen J.K., Jenkins P., Bloch D. \& Ingimarsson F. 2014. A review of the occurrence of bats (Chiroptera) on islands in the North East Atlantic and on North Sea installations. Acta Cropterologica 16: 169-195.

Rydell J., Bach L., Dubourg-Savage M.-J., Green M., Rodrigues L. \& Hedenstrom A. 2010a. Bat mortality at wind turbines in northwestern Europe. Acta Chiropterolo- gica, 12: 261-274.

Rydell J., Bach L., Dubourg-Savage M.-J., Green M., Rodrigues L. \& Hedenstrom A. 2010b. Mortality of bats at wind turbines links to nocturnal insect migration? Eur. J. Wildlife Research 56: 823-827.

Skiba R. 2007. Die Fledermäuse im Bereich der Deutschen Nordsee unter Berücksichtigung der Gefährdungen durch Windenergieanlagen (WEA). Nyctalus (Neue Folge) 12: 199-220.

Teunissen W. \& Veling K. 2013. Vlinders komen massaal vanaf zee vliegen. https://www.naturetoday.com/intl/nl/nature-reports/message/?msg=18205

Walter G., Matthes H. \& Joost M. 2007. Fledermauszug über Nord- und Ostsee - Ergebnisse aus OffshoreUntersuchungen und deren Einordnung in das bisher bekannte Bild zum Zuggeschehen. Nyctalus (Neue Folge) 12: 221-223. 


\section{Justification}

Report C062/19

Project Number: 4315100065

The scientific quality of this report has been peer reviewed by a colleague scientist and a member of the Management Team of Wageningen Marine Research

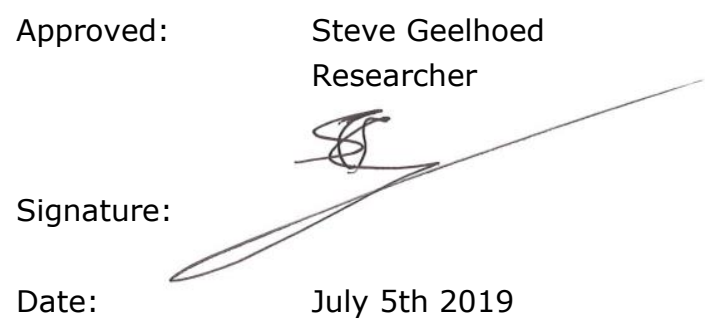

$\begin{array}{ll}\text { Approved: } & \text { Jakob Asjes } \\ \text { Manager integration }\end{array}$ 


\section{Annex 1 Batcorder results 2017 -2018}

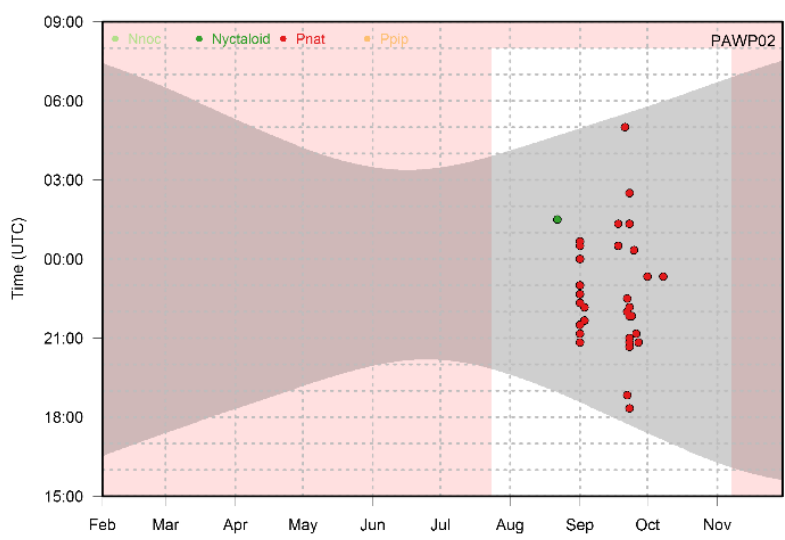

Figure A.1 Date/time plot PAWP OHVS 2017 (Batcorder)

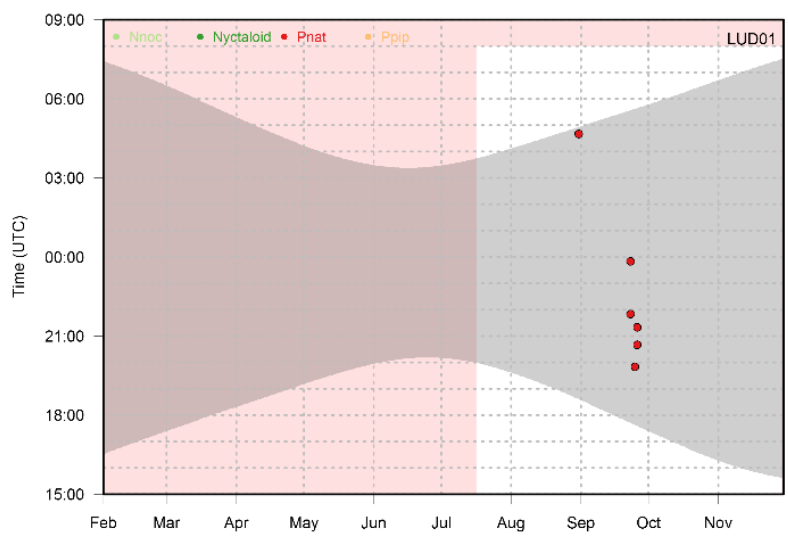

Figure A.3 Date/time plot LUD OHVS 2017 (Batcorder)

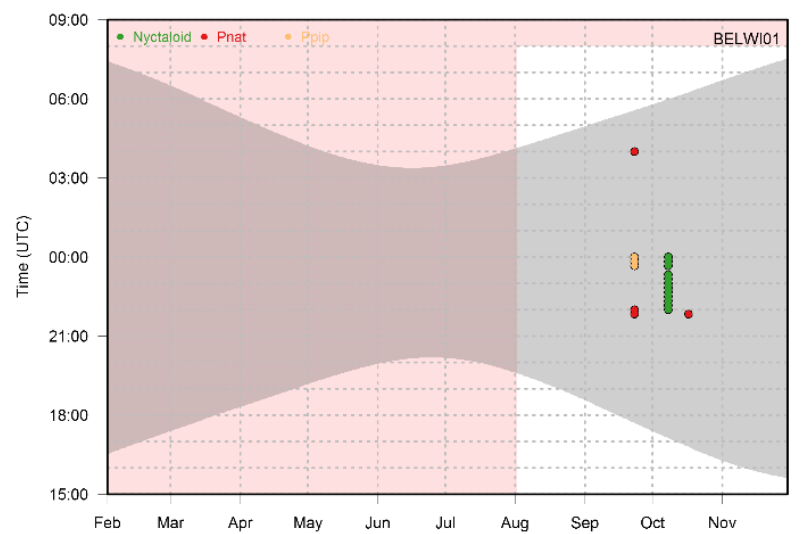

Figure A.5 Date/time plot Belwind 2017 (Batcorder)

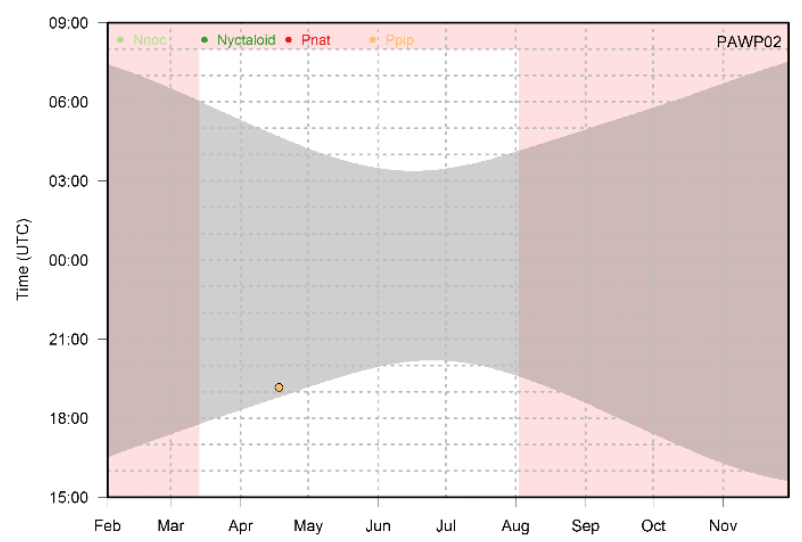

Figure A.2 Date/time plot PAWP OHVS 2018 (Batcorder)

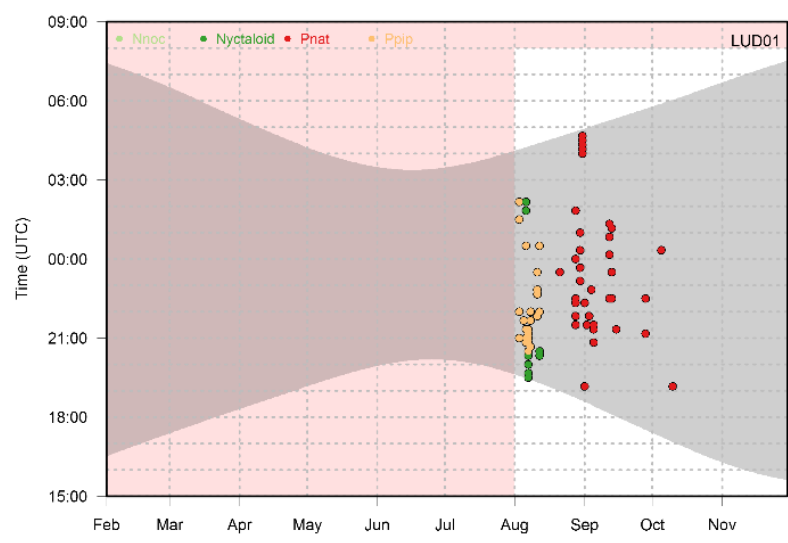

Figure A.4 Date/time plot LUD OHVS 2018 (Batcorder)

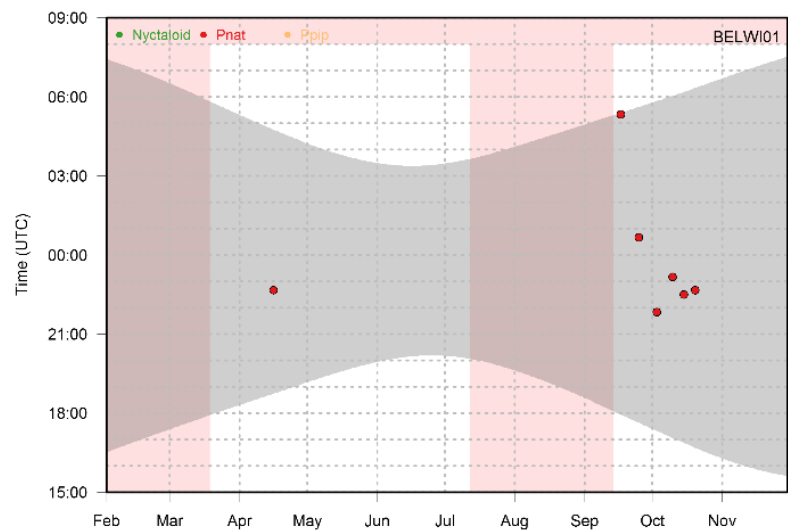

Figure A.6 Date/time plot Belwind 2018 (Batcorder) 


\section{Annex 2 Monitoring periods 2012 - 2018}

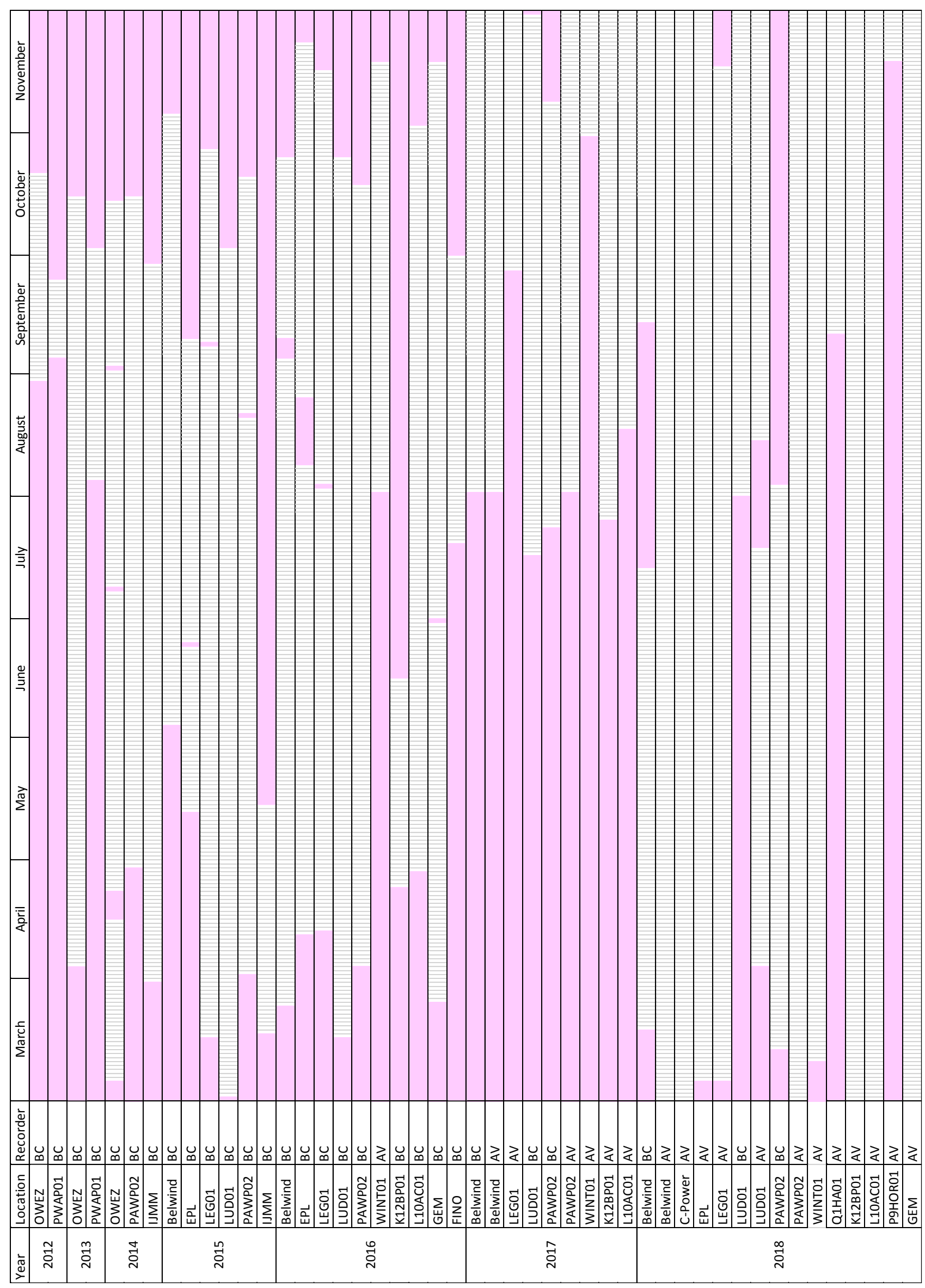




\section{Annex 3 Multiple individuals}

Recordings of Nathusius' pipistrelles with at least two individuals present simultaneously.

\begin{tabular}{l|l|l} 
Monitoring location & \multicolumn{2}{c}{ Time (UTC) } \\
\hline Neptune - L10 & $18-09-2017$ & $10: 30: 16$ \\
\hline LEG & $18-10-2017$ & $20: 20: 29$ \\
\hline Neptune - L10 & $19-04-2018$ & $19: 14: 27$ \\
\hline Neptune - L10 & $19-04-2018$ & $19: 14: 40$ \\
\hline Neptune - L10 & $19-04-2018$ & $19: 19: 13$ \\
\hline Neptune - L10 & $19-04-2018$ & $19: 19: 36$ \\
\hline Neptune - L10 & $19-04-2018$ & $19: 19: 44$ \\
\hline Neptune - L10 & $19-04-2018$ & $19: 19: 59$ \\
\hline Neptune - L10 & $19-04-2018$ & $19: 20: 22$ \\
\hline LEG & $10-04-2018$ & $21: 57: 22$ \\
\hline LEG & $10-04-2018$ & $22: 03: 47$ \\
\hline LEG & $10-04-2018$ & $22: 05: 16$ \\
\hline LEG & $10-04-2018$ & $22: 06: 00$ \\
\hline LEG & $10-04-2018$ & $22: 18: 57$ \\
\hline LEG & $10-04-2018$ & $22: 19: 12$ \\
\hline
\end{tabular}


Wageningen Marine Research

T +31 (0)317480900

E: marine-research@wur.nl

www.wur.eu/marine-research

Visitors' address

- Ankerpark 271781 AG Den Helder

- Korringaweg 7, 4401 NT Yerseke

- Haringkade 1, 1976 CP IJmuiden
With knowledge, independent scientific research and advice, Wageningen Marine Research substantially contributes to more sustainable and more careful management, use and protection of natural riches in marine, coastal and freshwater areas.
Wageningen Marine Research is part of Wageningen University \& Research. Wageningen University \& Research is the collaboration between Wageningen University and the Wageningen Research Foundation and its mission is: 'To explore the potential for improving the quality of life' 